\title{
Opioid-Induced Hyperalgesic Priming in Single Nociceptors
}

\author{
${ }^{\circledR}$ Eugen V. Khomula, ${ }^{\circ}$ Dionéia Araldi, ${ }^{\circledR}$ Ivan J. M. Bonet, and ${ }^{\circledR}$ Jon D. Levine \\ Departments of Medicine and Oral and Maxillofacial Surgery, Division of Neuroscience, and UCSF Pain and Addiction Research Center, University \\ of California at San Francisco, San Francisco, California 94143
}

Clinical $\mu$-opioid receptor (MOR) agonists produce hyperalgesic priming, a form of maladaptive nociceptor neuroplasticity, resulting in pain chronification. We have established an in vitro model of opioid-induced hyperalgesic priming (OIHP), in male rats, to identify nociceptor populations involved and its maintenance mechanisms. OIHP was induced in vivo by systemic administration of fentanyl and confirmed by prolongation of prostaglandin $\mathrm{E}_{2}\left(\mathrm{PGE}_{2}\right)$ hyperalgesia. Intrathecal cordycepin, which reverses Type I priming, or the combination of Src and mitogen-activated protein kinase (MAPK) inhibitors, which reverses Type II priming, both partially attenuated OIHP. Parallel in vitro experiments were performed on small-diameter $(<30 \mu \mathrm{m})$ dorsal root ganglion (DRG) neurons, cultured from fentanyl-primed rats, and rats with OIHP treated with agents that reverse Type I or Type II priming. Enhancement of the sensitizing effect of a low concentration of PGE 2 (10 nM), another characteristic feature of priming, measured as reduction in action potential (AP) rheobase, was found in weakly isolectin B4 (IB4)-positive and IB4-negative (IB4-) neurons. In strongly IB4-positive (IB4+) neurons, only the response to a higher concentration of $\mathrm{PGE}_{2}(100 \mathrm{nM})$ was enhanced. The sensitizing effect of $10 \mathrm{nM} \mathrm{PGE}_{2}$ was attenuated in weakly IB4+ and IB4- neurons cultured from rats whose OIHP was reversed in vivo. Thus, in vivo administration of fentanyl induces neuroplasticity in weakly IB4+ and IB4- nociceptors that persists in vitro and has properties of Type I and Type II priming. The mechanism underlying the enhanced sensitizing effect of $100 \mathrm{~nm} \mathrm{PGE}_{2}$ in strongly IB4+ nociceptors, not attenuated by inhibitors of Type I and Type II priming, remains to be elucidated.

Key words: excitability; fentanyl; isolectin B4; neuroplasticity; nociceptor; sensitization

Significance Statement

Commonly used clinical opioid analgesics, such as fentanyl and morphine, can produce hyperalgesia and chronification of pain. To uncover the nociceptor population mediating opioid-induced hyperalgesic priming (OIHP), a model of pain chronification, and elucidate its underlying mechanism, at the cellular level, we established an in vitro model of OIHP. In dorsal root ganglion (DRG) neurons cultured from rats primed with fentanyl, robust nociceptor population-specific changes in sensitization by prostaglandin $\mathrm{E}_{2}\left(\mathrm{PGE}_{2}\right)$ were observed, when compared with nociceptors from opioid naive rats. In DRG neurons cultured from rats with $\mathrm{OIHP}$, enhanced $\mathrm{PGE}_{2}$-induced sensitization was observed in vitro, with differences identified in nonpeptidergic [strongly isolectin B4 (IB4)-positive] and peptidergic [weakly IB4-positive (IB4+) and IB4-negative (IB4-)] nociceptors.

\section{Introduction}

Opioid analgesics remain among the most effective treatments for moderate-to-severe pain (Manchikanti et al., 2012; Cheung et al., 2014; Ballantyne, 2015; Bicket et al., 2019; Pisanu et al., 2019; Preuss et al., 2020). They can, however, produce serious adverse effects, including analgesic tolerance, addiction, opioid-induced hyperalgesia $(\mathrm{OIH})$, and pain chronification (Ossipov et al.,

\footnotetext{
Received Aug. 17, 2020; revised Sep. 23, 2020; accepted Nov. 1, 2020.

Author contributions: E.V.K., D.A., I.J.M.B., and J.D.L. designed research; E.V.K., D.A., and I.J.M.B.

performed research; E.V.K. and D.A. analyzed data; E.V.K., D.A., and J.D.L. wrote the paper.

This work was supported by the National Institutes of Health Grant NS084545.

The authors declare no competing financial interests.

Correspondence should be addressed to Jon D. Levine at jon.levine@ucsf.edu.

https://doi.org/10.1523/JNEUROSCI.2160-20.2020

Copyright $\odot 2021$ the authors
}

2005; Chu et al., 2006; De Felice and Porreca, 2009; Roeckel et al., 2016; Mercadante et al., 2019), which limits their use and contributes to their abuse. Even when opioid analgesics are used briefly, in the perioperative period, they may lead to increased, postoperative pain and opioid requirements, up to a year later (Chia et al., 1999; van Gulik et al., 2012; Rashiq and Dick, 2014; Yildirim et al., 2014; Lyons et al., 2015; Chang et al., 2018; Rong et al., 2019), indicating that opioids can produce long-lasting alterations in pain processing, well beyond the duration of opioid exposure. We have established a preclinical model of the transition from acute to chronic pain, hyperalgesic priming, here referred to as priming. Priming is a form of long-lasting nociceptor neuroplasticity manifested by a left-shift in dose dependence and marked prolongation of mechanical hyperalgesia in response to pronociceptive mediators, prototypically prostaglandin $\mathrm{E}_{2}$ 
( $\mathrm{PGE}_{2}$ ), but unchanged baseline nociceptive threshold (Aley et al., 2000; Parada et al., 2003, 2005; Reichling and Levine, 2009; Araldi et al., 2015, 2017a, 2018b,c, 2019; Ferrari et al., 2015, 2019; Khomula et al., 2017). Thus, while in control rats $\mathrm{PGE}_{2^{-}}$ induced hyperalgesia is of short duration $(<4 \mathrm{~h})$, in the primed state hyperalgesia is produced by lower concentrations of $\mathrm{PGE}_{2}$ (Parada et al., 2003, 2005) and is still present, unattenuated, $4 \mathrm{~h}$ later (Aley et al., 2000).

We have recently shown that $\mu$-opioid receptor (MOR) agonists, including two commonly used clinical opioids, fentanyl (Araldi et al., 2018c; Khomula et al., 2019) and morphine (Araldi et al., 2019; Ferrari et al., 2019), as well as two biased MOR agonists, PZM21 and TRV130 (Araldi et al., 2018a), can produce both $\mathrm{OIH}$ and opioid-induced hyperalgesic priming (OIHP). We have recently established an in vitro model of $\mathrm{OIH}$, neuroplasticity induced by in vivo administration of fentanyl that persists in cultured DRG neurons, differentially affecting peptidergic and non-peptidergic nociceptors (Khomula et al., 2019). However, despite a growing literature obtained from in vivo experiments, lack of an in vitro model of OIHP has made it difficult to study underlying mechanisms at the cellular level, in identified nociceptor populations.

Primary afferent nociceptors can be divided into three categories based on isolectin B4 (IB4)-binding status: strongly IB4-positive (IB4+), weakly IB4+, and IB4-negative (IB4-; Kashiba et al., 2001; Fang et al., 2006). IB4+ neurons depend on glialderived neurotrophic factor (GDNF), and express Ret, whereas IB4- neurons depend on NGF for survival and express TrkA (Molliver et al., 1997; Bennett et al., 1998; Kashiba et al., 1998). Weakly IB4+ neurons also express TrkA (Kashiba et al., 2001; Fang et al., 2006). Nociceptors can also be classified into nonpeptidergic and peptidergic (Bennett et al., 1996; Molliver et al., 1997; Woolf and Ma, 2007). Strongly IB4+ nociceptors belong to the non-peptidergic class, whereas weakly IB4+ and IB4nociceptors are peptidergic (Kashiba et al., 2001; Fang et al., 2006). These classes differ in electrophysiological properties (Stucky and Lewin, 1999), physiological function (Snider and McMahon, 1998), and their role in OIHP (Araldi et al., 2015, 2018c, 2019; Ferrari et al., 2019).

To establish an in vitro model of OIHP we (1) produced OIHP in vivo, assessed at the nociceptor peripheral and central terminal as prolongation of $\mathrm{PGE}_{2}$-induced mechanical hyperalgesia, in rats treated with systemic fentanyl; (2) established, in vivo, a protocol to reverse OIHP and also evaluate whether systemic fentanyl-induced priming occurs in peptidergic and/or nonpeptidergic neurons; (3) employed, in vitro, concentration dependence of $\mathrm{PGE}_{2}$-induced sensitization, in populations of cultured DRG neurons (i.e., strongly and weakly IB4+, and IB4-) from rats primed in vivo with systemic fentanyl, to reveal in vitro correlates of OIHP at the single cell level; and (4) tested putative maintenance mechanisms of OIHP in nociceptor populations classified by their IB4-binding status (based on in vitro correlates, in cultured DRG neurons from animals in which OIHP was reversed in vivo).

\section{Materials and Methods}

\section{Animals}

Experiments were performed on 220-420 g male Sprague Dawley rats (Charles River Laboratories). Experimental animals were housed three per cage, under a 12/12 h light/dark cycle, in a temperature-controlled and humidity-controlled animal care facility at the University of California, San Francisco. Food and water were available ad libitum. Nociceptive testing was performed between 9 A.M. and 5 P.M. All experimental protocols approved by the Institutional Animal Care and Use
Committee at the University of California, San Francisco and adhered to the National Institutes of Health Guide for the Care and Use of Laboratory Animals. Effort was made to minimize number of animals used and their suffering.

\section{Nociceptive threshold testing}

Mechanical nociceptive threshold was measured using an Ugo Basile Analgesymeter (Randall-Selitto paw-withdrawal device, Stoelting), which applies a linearly increasing mechanical force to the dorsum of a rat's hind paw, with a dome-shaped plinth, as previously described (Taiwo et al., 1989; Taiwo and Levine, 1989; Araldi et al., 2015, 2017a; Ferrari and Levine, 2015). Rats were placed in cylindrical acrylic restrainers that provide ventilation, and lateral ports that allow extension of their hind legs for the assessment of nociceptive threshold, while minimizing restraint stress. To acclimatize rats to the testing procedure, they were placed in restrainers for $40 \mathrm{~min}$ before starting training sessions (three consecutive days of training) and for $30 \mathrm{~min}$ before experimental manipulations. Nociceptive threshold was defined as the force, in grams, at which the rat withdrew its paw. Baseline nociceptive threshold for each individual rat was defined as the mean of three readings taken before the first experimental treatment. In each experiment, only one paw per rat was used. Each experiment was performed on a different group of rats (one paw/rat, six rats/group). The individuals performing behavioral experiments (D.A. and I.J.M.B.) were blinded to treatments.

\section{Drugs and routes of administration}

The following compounds were used in these experiments: cordycepin 5 '-triphosphate sodium salt (a protein translation inhibitor), fentanyl citrate salt (a MOR agonist), SU6656 (a Src family kinase inhibitor), U0126 [a MAPK/extracellular signal-regulated kinase [ERK] inhibitor], and $\mathrm{PGE}_{2}$ (a direct-acting nociceptor-sensitizing agent), all of which were purchased from Sigma-Aldrich.

A stock solution of $\mathrm{PGE}_{2}(1 \mu \mathrm{g} / \mu \mathrm{l})$ was prepared in $100 \%$ ethanol and additional dilutions made with physiological saline $(0.9 \% \mathrm{NaCl})$, to prepare the final solution used in experiments $(100 \mathrm{ng} / 5 \mu \mathrm{l})$, which yielded a final ethanol concentration of $2 \%$. In previous in vivo control experiments, we have shown that ethanol in this concentration had no effect on mechanical nociceptive threshold (Ferrari et al., 2016). Fentanyl and cordycepin were dissolved in saline. SU6656 and U0126 were dissolved in 100\% dimethylsulfoxide (DMSO; Sigma-Aldrich) and further diluted in saline containing 2\% Tween 80 (Sigma-Aldrich). The final concentration of DMSO and Tween 80 was $\sim 2 \%$.

Intradermal administration of $\mathrm{PGE}_{2}(100 \mathrm{ng} / 5 \mu \mathrm{l})$ was performed on the dorsum of the hindpaw using a 30-gauge hypodermic needle adapted to a $50 \mu$ Hamilton syringe by a segment of PE-10 polyethylene tubing (Becton Dickinson).

Intrathecal administration of $\mathrm{PGE}_{2}$, cordycepin, the combination of SU6656 and U0126, and the combination of cordycepin, SU6656, and U0126 was performed in rats briefly anesthetized with $2.5 \%$ isoflurane (Phoenix Pharmaceuticals) in $97.5 \% \mathrm{O}_{2}$, using a 29 -gauge hypodermic needle (300 unit/ $\mu$ l syringe; Walgreens Pharmacy) inserted into the subarachnoid space, between the L4 and L5 vertebrae. The maximum intrathecal volume administered was $20 \mu \mathrm{l}$; cordycepin $(4 \mu \mathrm{g})$ was dissolved in saline and injected intrathecally in a volume of $20 \mu \mathrm{l}$, when followed by intradermal $\mathrm{PGE}_{2}(100 \mathrm{ng} / 5 \mu \mathrm{l})$, and in a volume of $10 \mu \mathrm{l}$ when followed by intrathecal PGE 2 ( $400 \mathrm{ng} / 10 \mu \mathrm{l}$; Araldi et al., 2018c). The combination of SU6656 $(10 \mu \mathrm{g})$ and U0126 $(10 \mu \mathrm{g})$ was injected intrathecally in a final volume of 20 or $10 \mu$ l (these drugs were mixed in the syringe at the moment of injection), followed by $\mathrm{PGE}_{2}$ injected intradermally $(100 \mathrm{ng} / 5 \mu \mathrm{l})$ or intrathecally $(400 \mathrm{ng} / 10 \mu \mathrm{l})$, respectively. The combination of all three inhibitors [cordycepin $(4 \mu \mathrm{g} / 6 \mu \mathrm{l})$, SU6656 $(10 \mu \mathrm{g} / 6 \mu \mathrm{l})$, and $\operatorname{U0126}(10 \mu \mathrm{g} / 6 \mu \mathrm{l})$ ] was injected intrathecally followed, $10 \mathrm{~min}$ later, by intradermal $\mathrm{PGE}_{2}(100 \mathrm{ng} / 5 \mu \mathrm{l})$. To verify whether the inhibitors reversed systemic fentanyl-induced priming permanently, $\mathrm{PGE}_{2}$ was again injected intradermally $(100 \mathrm{ng} / 5 \mu \mathrm{l})$ or intrathecally (400 ng/20 $\mu \mathrm{l}), 4,14$, and 28 days after the inhibitors. The intrathecal site of injection was confirmed by a sudden flick of the rat's tail, a reflex that is evoked by accessing the subarachnoid space followed by bolus intrathecal injection (Mestre et al., 1994). 
Systemic (subcutaneous) administration of fentanyl was performed at the nape of the neck (Araldi et al., 2018c, 2019). Rats received an injection of fentanyl $(30 \mu \mathrm{g} / \mathrm{kg}$, s.c.) diluted in saline and administered subcutaneously $(100 \mu \mathrm{l} / 100 \mathrm{~g}$ body weight).

\section{Administration of saporins}

IB4-saporin

IB4-saporin, an IB4+ nociceptor neurotoxin (Advanced Targeting Systems), was diluted in saline and a dose of $3.2 \mu \mathrm{g}$, in a volume of $20 \mu \mathrm{l}$, administered intrathecally, $14 \mathrm{~d}$ before systemic administration of fentanyl $(30 \mu \mathrm{g} / \mathrm{kg})$. The dose and timing of IB4-saporin administration were chosen based on previous reports from our group and others (Vulchanova et al., 2001; Nishiguchi et al., 2004; Joseph et al., 2008, 2010; Araldi et al., 2015, 2016a, 2017b, 2018c).

\section{$\left[\mathrm{Sar}^{9}, \mathrm{Met}\left(\mathrm{O}_{2}\right)^{11}\right]$-substance P-saporin (SSP-saporin)}

SSP-saporin, a neurotoxin specifically targeting neurons that express substance P (SP) receptors (Advanced Targeting Systems), was diluted in saline and a dose of $100 \mathrm{ng}$ in a volume of $20 \mu \mathrm{l}$ administered intrathecally $14 \mathrm{~d}$ before rats received a systemic fentanyl $(30 \mu \mathrm{g} / \mathrm{kg})$. The addition of $\left[\mathrm{Sar}^{9}, \operatorname{Met}\left(\mathrm{O}_{2}\right)^{11}\right]$ to the SP-conjugated to saporin makes the agent more stable and potent than when SP alone is bound to saporin. The dose and time point of the treatment ( $14 \mathrm{~d}$ before fentanyl) were based on previous studies (Wiley et al., 2007; Choi et al., 2012), where there was observed loss of intrinsic lumbar dorsal horn neurons expressing neurokinin 1 receptor (NK1R), a receptor for SP, in Laminae I-III but not in deeper laminae (Khasabov et al., 2002; Vierck et al., 2003; Wiley et al., 2007; Choi et al., 2012; Weisshaar and Winkelstein, 2014; Kras et al., 2015; Araldi et al., 2016b, 2017b, 2018b,c), thus disrupting signaling dependent on peptidergic nociceptors (Seki et al., 2005).

We used rats treated with unconjugated saporin as controls, since previous studies demonstrated that intrathecal administration of saporin alone has no effects on NK1R staining in the spinal cord (Hwang et al., 2003) and does not decrease IB4 labeling in Lamina II of the dorsal horn (Joseph et al., 2008). The control group received $3.2 \mu \mathrm{g}$ of unconjugated saporin, diluted in $20 \mu \mathrm{l}$ of saline, intrathecally. This dose $(3.2 \mu \mathrm{g})$ is equal to the IB4-saporin dose and higher than SSP-saporin (100 ng).

To inject unconjugated saporin, IB4-saporin, or SSP-saporin, rats were briefly anesthetized with $2.5 \%$ isoflurane (Phoenix Pharmaceuticals) in $97.5 \% \mathrm{O}_{2}$, and then a 29 -gauge hypodermic needle (300 units/ $\mu$ syringe, Walgreens Pharmacy) was inserted, on the midline, into the subarachnoid space, between the L4 and L5 vertebrae. Rats regained consciousness $\sim 2$ min after stopping anesthesia. There was no effect of unconjugated saporin, IB4-saporin, or SSP-saporin on mechanical nociceptive threshold per se $\left(t_{(5)}=0.6 ; p=0.59\right.$, for the unconjugated saporin-treated group, $t_{(5)}=1.3 ; p=0.24$, for the SSP-saporin-treated group, and $t_{(5)}=0.5 ; p=0.66$, for the IB4-saporin-treated group, when the mechanical nociceptive threshold is compared before and $14 \mathrm{~d}$ after intrathecal saporins; paired Student's $t$ test).

\section{Culture of DRG neurons}

Primary cultures of dorsal root ganglion (DRG) neurons were made from adult male Sprague Dawley rats $(220-235 \mathrm{~g})$, as described previously (Ferrari et al., 2016, 2018; Khomula et al., 2017; Araldi et al., 2018c). In brief, under isoflurane anesthesia, rats were decapitated, and the dorsum of the vertebral column surgically removed; $\mathrm{L}_{4}$ and $\mathrm{L}_{5}$ DRGs were rapidly extracted, bilaterally, chilled, and desheathed in HBSS, on ice. Ganglia were then treated with $0.25 \%$ collagenase type 4 (Worthington Biochemical Corporation) in HBSS for $18 \mathrm{~min}$ at $37^{\circ} \mathrm{C}$, and then treated with $0.25 \%$ trypsin (Worthington Biochemical Corporation) in calciumfree and magnesium-free PBS (Invitrogen Life Technologies) for $6 \mathrm{~min}$, followed by three washes, and then trituration in Neurobasal-A medium (Invitrogen Life Technologies) to produce a single-cell suspension. This suspension was centrifuged at 1000 RPM for $3 \mathrm{~min}$ and re-suspended in Neurobasal-A medium supplemented with $50 \mathrm{ng} / \mathrm{ml}$ nerve growth factor, $100 \mathrm{U} / \mathrm{ml}$ penicillin/streptomycin, B-27, GlutaMAX, and 10\% fetal bovine serum (Invitrogen Life Technologies). Cells were then plated on cover slips and incubated at $37^{\circ} \mathrm{C}$ in $3.5 \% \mathrm{CO}_{2}$ for at least $24 \mathrm{~h}$ before use in experiments.

\section{In vitro patch-clamp electrophysiology}

Cultured DRG neurons were used in in vitro electrophysiology experiments 24-96 h after DRG dissociation and plating. DRG from at least three rats (separate culture preparations) were used for each experimental series. Within the text, $n$ refers to the number of neurons. Cells were identified as neurons by their double birefringent plasma membranes (Cohen et al., 1968; Landowne, 1993). While small, medium, and large sized DRG neurons were routinely observed in the same preparation, this study focused on cells with a soma diameter $<30 \mu \mathrm{m}$ (small DRG neurons), predominantly representing C-type nociceptors (Harper and Lawson, 1985; Gold et al., 1996b; Petruska et al., 2000, 2002; Woolf and Ma, 2007). After mounting a coverslip with cells in the recording chamber, the culture medium was replaced with Tyrode's solution containing $140 \mathrm{~mm} \mathrm{NaCl}, 4 \mathrm{~mm} \mathrm{KCl}, 2 \mathrm{~mm} \mathrm{MgCl}$, 2 mM CaCl, $10 \mathrm{~mm}$ glucose, and $10 \mathrm{~mm}$ HEPES and adjusted to $\mathrm{pH} 7.4$ with $\mathrm{NaOH}$; osmolarity is 310 $\mathrm{mOsm} / \mathrm{kg}$ (Ferrari et al., 2016, 2018; Khomula et al., 2017; Araldi et al., 2018c). Tyrode's solution was used as external perfusion solution in the in vitro experiments. Drugs used in vitro were diluted to their final concentration in this solution just before application. The volume of the recording chamber is $150 \mu$ l. The perfusion system is gravity-driven, flow rate of $0.5-1 \mathrm{ml} / \mathrm{min}$. All experiments were performed at room temperature $\left(20-23^{\circ} \mathrm{C}\right)$.

Whole-cell patch-clamp recordings, in current clamp mode, were made to assess changes in the excitability of cultured DRG neurons. Holding current was adjusted to maintain membrane potential at $-70 \mathrm{mV}$. Rheobase, the minimum magnitude of a current step needed to elicit an action potential (AP), was determined from a protocol using increasing square wave current pulses. To estimate rheobase, a series of current steps with 200-pA increments was applied until APs were elicited. The protocol was then adjusted to five to six pulses with step size of $5-10 \%$ of the rheobase estimate (two to three subthreshold stimuli and two to three with AP generation, to avoid overstimulation/desensitization; Ferrari et al., 2018; Khomula et al., 2019).

Recording electrodes were fabricated from borosilicate glass capillaries (0.84/1.5 mm i.d./o.d., Warner Instruments, LLC) using a Flaming/ Brown P-87 puller (Sutter Instrument Co). Recording electrode resistance was $\sim 3 \mathrm{M} \Omega$ after being filled with a solution containing the following: $130 \mathrm{~mm} \mathrm{KCl}, 10 \mathrm{~mm}$ HEPES, $10 \mathrm{~mm}$ EGTA, $1 \mathrm{~mm} \mathrm{CaCl}_{2}, 5 \mathrm{~mm}$ MgATP, and $1 \mathrm{~mm}$ Na-GTP; pH 7.2 (adjusted with Tris-base), 300 mOsm (measured by Wescor Vapro 5520 osmometer, ELITech Group; Ferrari et al., 2018). Junction potential was not adjusted. Series resistance was below $20 \mathrm{M} \Omega$ at the end of recordings and was not compensated. Recordings were made with an Axon MultiClamp 700 B amplifier, filtered at $10 \mathrm{kHz}$, and sampled at $20 \mathrm{kHz}$ using Axon Digidata 1550B controlled by pCLAMP 11 software (all from Molecular Devices LLC).

Drugs were applied at least $10 \mathrm{~min}$ after the establishment of whole cell configuration, at which time baseline current was stable.

\section{Identification of priming in vitro}

We have previously shown that $\mathrm{PGE}_{2}$ sensitizes small-diameter DRG neurons, putative nociceptors, in vitro (Gold et al., 1996b,c, 1998). Within 1-2 min, sensitization can be detected in "whole-cell" patched neurons, in current clamp mode, as a reduction of rheobase, the minimal sustained current required to generate an $\mathrm{AP}$, for a saturating concentration of $\mathrm{PGE}_{2}(1 \mu \mathrm{M})$, in both IB4- and IB4+ small-diameter DRG neurons (Gold et al., 1996b; Ferrari et al., 2018). Since it is not practical to hold cells "clamped" for $4 \mathrm{~h}$, to reveal priming, we relied on another in vivo feature of hyperalgesic priming, a more than one order magnitude leftward shift (to lower values) for the dose dependence of $\mathrm{PGE}_{2}$-induced hyperalgesia (Parada et al., 2005). Since only $\sim 60 \%$ of cultured DRG neurons are responsive to $\mathrm{PGE}_{2}$ (Gold et al., 1996b), it would not be possible to distinguish between responsive and nonresponsive neurons by their response to a low concentration of $\mathrm{PGE}_{2}$; response to a higher concentration is required. Previously, it has been shown that the dose dependence for the in vitro sensitizing effect of $\mathrm{PGE}_{2}$ ranges from concentrations of $1 \mathrm{~nm}$ to $1 \mu \mathrm{M}$ (Gold et al., 1996b). Therefore, we chose two $\mathrm{PGE}_{2}$ concentrations, 10 and $100 \mathrm{nM}$, to examine our hypothesis that priming in vivo induces a leftward shift of the dose response curve in primed DRG neurons. 


\section{Fluorescence imaging of in vitro IB4 binding}

The bright-field imaging system consisted of an inverted microscope (Eclipse TE-200, Nikon Instruments Inc) with epi-fluorescence using a xenon lamp (Lambda LS, Sutter Instruments Co) for excitation (Ferrari et al., 2018). Illumination was controlled by a Lambda 10-2 filter wheel and Lambda SC Smart Shutter controllers (Sutter Instruments Co); an Andor Clara Interline CCD camera (Andor Technology Ltd.) was used for high-resolution digital image acquisition. MetaFluor software (Molecular Devices LLC) provided computer interface and controlled the whole system as well as being used for image processing. A Plan Fluor objective (20× UV, NA 0.50; Nikon Instruments Inc) was used for both fluorescent and transmitted light imaging with phase contrast illumination.

Cells were incubated in Tyrode's solution supplemented with $10 \mu \mathrm{g} /$ $\mathrm{ml}$ IB4 conjugated to Alexa Fluor 488 dye (Invitrogen Life Technologies) for 10-12 min, in the dark. After washout, fluorescent images were captured during the first $15 \mathrm{~min}$ of each experiment using a standard GFP filter set (Chroma Technology). Cells demonstrating bright fluorescence and a halo around the neuronal plasma membrane were recognized as IB4+ (strongly positive, if intensity above $40 \%$ of maximum for the selected field of view, and weakly positive if intensity in the range 20$40 \%$ of maximum), whereas those having intensity below $20 \%$ of maximum were considered as IB4- (Fang et al., 2006; Khomula et al., 2013, 2017, 2019; Ferrari et al., 2016).

\section{Data analysis}

All data are presented as mean \pm SEM of $n$ independent observations. In all figures bars show mean and error bars show SEM. Statistical comparisons were made using GraphPad Prism 8.0 statistical software (GraphPad Software Inc); $p<0.05$ was considered statistically significant.

In behavioral experiments, the dependent variable was mechanical paw-withdrawal threshold. Each data point was the mean of three readings. All magnitudes were expressed as percentage change from baseline. Average mechanical nociceptive threshold before systemic fentanyl was $143.4 \pm 1.3 \mathrm{~g}$ and $4 \mathrm{~d}$ after was $142.8 \pm 1.14\left(n=60\right.$ rats; $t_{(59)}=0.48$, $p=0.64$, paired Student's $t$ test).

In electrophysiological experiments, magnitude of the sensitizing effect of $\mathrm{PGE}_{2}$ was expressed as percentage reduction in rheobase (relative to a baseline rheobase value recorded before $\mathrm{PGE}_{2}$ administration). Only neurons sensitized above $10 \%$ by $10 \mathrm{~min}$ after $\mathrm{PGE}_{2}$, at the lower $(10 \mathrm{nM})$ or higher $(100 \mathrm{nM})$ concentration, applied to the same neuron, were considered $\mathrm{PGE}_{2}$ responsive, and included in our analysis.

As described in detail in the figure legends, the following statistical tests were used: paired (Fig. 1) and unpaired (Fig. 5C) Student's $t$ test, two-way repeated-measures ANOVA followed by Bonferroni's post hoc test (Figs. 1-3), one-way ANOVA followed by Tukey's post hoc test (Figs. $6 D, 7 D, 8$ ), two-way ANOVA followed by Holm-Sidak's post hoc test (Figs. $5 A, B, D, 6 A-C, 7 A-C$ ).

\section{Results}

\section{Systemic fentanyl induces Type I and Type II priming at the nociceptor peripheral terminal}

We recently demonstrated the presence of OIH and OIHP, in vivo, at the nociceptor peripheral terminal after a single systemic (subcutaneous) injection of an analgesic dose of fentanyl $(30 \mu \mathrm{g} /$ $\mathrm{kg}$; Khomula et al., 2019). We also demonstrated that OIH, induced by systemic fentanyl, is attenuated by administration of cordycepin at the peripheral terminal (Khomula et al., 2019), indicative of Type I priming (Ferrari et al., 2013). More recently, we identified a second type of hyperalgesic priming, referred to as Type II (Araldi et al., 2015, 2018c). In distinction to the maintenance mechanisms for Type I priming (Ferrari et al., 2013), Type II is dependent on the combined activation of Src and MAP kinases (Araldi et al., 2017a). While we recently demonstrated that $\mathrm{OIH}$ induced by systemic fentanyl is reversed by cordycepin (Khomula et al., 2019), the maintenance mechanism of
OIHP has not been tested. Therefore, we evaluated, using the same in vivo model, whether hyperalgesic priming in the peripheral terminal is Type I (reversed by cordycepin) or Type II (reversed by the combination of Src and MAPK inhibitors).

Rats received a systemic injection of fentanyl $(30 \mu \mathrm{g} / \mathrm{kg}$, s.c.) followed, $4 \mathrm{~d}$ later by intrathecal injection of vehicle $(20 \mu \mathrm{l})$, cordycepin $(4 \mu \mathrm{g} / 20 \mu \mathrm{l})$, the combination of Src (SU6656, $10 \mu \mathrm{g}$ / $10 \mu \mathrm{l})$ and MAPK $(\mathrm{U} 0126,10 \mu \mathrm{g} / 10 \mu \mathrm{l})$ inhibitors, or a combination of all three drugs [cordycepin $(4 \mu \mathrm{g} / 6 \mu \mathrm{l})$, SU6656 $(10 \mu \mathrm{g} /$ $6 \mu \mathrm{l})$, and U0126 $(10 \mu \mathrm{g} / 6 \mu \mathrm{l})]$. Ten minutes later, $\mathrm{PGE}_{2}(100 \mathrm{ng})$ was injected intradermally and mechanical nociceptive threshold evaluated a further $30 \mathrm{~min}$ and $4 \mathrm{~h}$ later. When measured $30 \mathrm{~min}$ after injection, $\mathrm{PGE}_{2}$-induced hyperalgesia in all groups. However, the prolongation of $\mathrm{PGE}_{2}$ hyperalgesia, measured at the fourth hour, was attenuated in the groups treated with cordycepin, SU6656 + U0126 or the combination of all three inhibitors $\left(F_{(3,20)}\right.$ $=10.8, p=0.0002$, when the vehicle-treated and inhibitors-treated groups are compared at the fourth hour after intradermal $\mathrm{PGE}_{2}$; two-way ANOVA multiple comparations test; Fig. 1A). To determine whether intrathecal administration of inhibitors was able to permanently attenuate priming induced by systemic fentanyl, the same groups of rats again received intradermal $\mathrm{PGE}_{2}(100 \mathrm{ng}), 4 \mathrm{~d}$ (Fig. 1B), $14 \mathrm{~d}$ (Fig. 1C), and $28 \mathrm{~d}$ (Fig. 1D) after vehicle or inhibitors. In the groups treated with cordycepin, the combination of SU6656 + U0126, and the combination of all three inhibitors, the prolongation of $\mathrm{PGE}_{2}$-induced hyperalgesia was attenuated, at all time points evaluated $[4 \mathrm{~d}$, (Fig. $1 B) F_{(3,20)}=23.6, p<0.0001$; $F_{(3,20)}=15.4, p<0.0001 ; 14 \mathrm{~d}$ (Fig. $\left.1 C\right) F_{(3,20)}=4.1, p=0.02$; and $28 \mathrm{~d}$ (Fig. 1D) $F_{(3,20)}=7.9, p=0.0011$, when the vehicle-treated group is compared with all the inhibitors-treated groups at the fourth hour after intradermal $\mathrm{PGE}_{2}$; two-way ANOVA multiple comparations test]. These results provide confirmation that the reversal effects of cordycepin, and the combination of Src and MAPK inhibitors persisted for at least $28 \mathrm{~d}$. In contrast, in the vehicle-treated group, priming did not reveal any attenuation out to day 32 after induction, as demonstrated by unattenuated magnitude of $\mathrm{PGE}_{2}$-induced hyperalgesia at $4 \mathrm{~h}$. Altogether, these findings indicate that in the peripheral terminal of the nociceptor, maintenance of OIHP produced by a single systemic administration of fentanyl $(30 \mu \mathrm{g} / \mathrm{kg})$, shares mechanisms with both Type I and Type II priming. Of note, the combination of all three inhibitors (cordycepin + SU6656 + U0126) did not produce additional attenuation of $\mathrm{PGE}_{2}$-induced hyperalgesia, at $4 \mathrm{~h}$, in systemic fentanyl-primed rats, when it was compared with the cordycepintreated and SU6656 + U0126-treated groups.

\section{Priming induced by systemic fentanyl in the central terminal of the nociceptor is Type II}

Systemic fentanyl at an analgesic dose $(30 \mu \mathrm{g} / \mathrm{kg})$ induces both Type I and Type II priming in the peripheral terminal of the nociceptor (Fig. 1). We next investigated the type of priming that systemic fentanyl induces in the central terminal. Rats received systemic fentanyl $(30 \mu \mathrm{g} / \mathrm{kg}$, s.c.) and $4 \mathrm{~d}$ later, vehicle $(10 \mu \mathrm{l})$, cordycepin $(4 \mu \mathrm{g} / 10 \mu \mathrm{l})$, or the combination of Src (SU6656, $10 \mu \mathrm{g} / 5 \mu \mathrm{l})$ and MAPK (U0126, $10 \mu \mathrm{g} / 5 \mu \mathrm{l})$ inhibitors was administered intrathecally, followed, 10 min later by $\mathrm{PGE}_{2}$ (400 ng/ $10 \mu \mathrm{l}$ ), injected at the same site. Mechanical nociceptive threshold was evaluated $30 \mathrm{~min}$ and $4 \mathrm{~h}$ after intrathecal $\mathrm{PGE}_{2}$. Measured 30 min after its administration, intrathecal $\mathrm{PGE}_{2}$ induced hyperalgesia in all groups. The prolongation of hyperalgesia induced by intrathecal $\mathrm{PGE}_{2}$ was markedly attenuated in the group treated with the combination of SU6656 + U0126, but not in the vehicle-treated and cordycepin-treated groups $\left(F_{(2,15)}=49.9\right.$, 

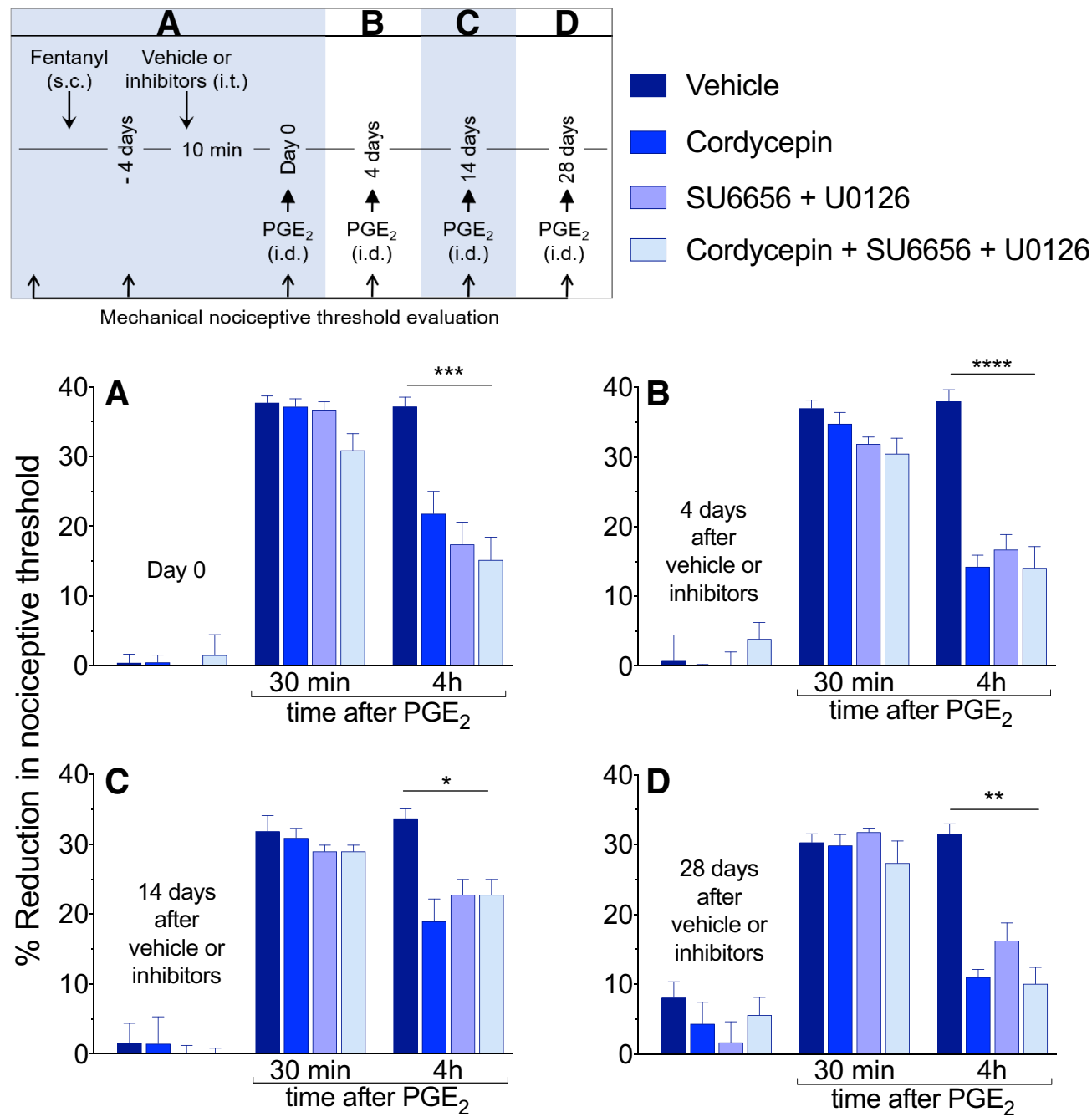

Figure 1. Hyperalgesic priming in the peripheral terminal of the nociceptor, induced by systemic fentanyl, is attenuated by inhibitors of protein translation and a combination of a Src and MAP kinases. $A$, Male rats received a single systemic injection of an analgesic dose of fentanyl ( $30 \mu \mathrm{g} / \mathrm{kg}$, s.c.). Four days later, at which time the mechanical nociceptive threshold was not different from pre-fentanyl baseline (Day $0 ; t_{(23)}=1.2 ; p=0.26$, when the mechanical nociceptive threshold is compared before and $4 \mathrm{~d}$ after systemic fentanyl; paired Student's $t$ test), vehicle (2\% DMSO in saline, $20 \mu \mathrm{l})$, cordycepin $(4 \mu \mathrm{g} / 20 \mu \mathrm{l})$, the combination of Src kinase inhibitor $(S U 6656,10 \mu \mathrm{g} / 10 \mu \mathrm{l})$ and MAPK inhibitor $(U 0126,10 \mu \mathrm{g} / 10 \mu \mathrm{l})$ or the combination of all three inhibitors (cordycepin + SU6656 + U0126: $4 \mu \mathrm{g} / 6 \mu \mathrm{l}, 10 \mu \mathrm{g} / 6 \mu \mathrm{l}$, and $10 \mu \mathrm{g} / 6 \mu \mathrm{l}$, respectively) was administered intrathecally followed, 10 min later, by PGE $(100 \mathrm{ng} / 5 \mu \mathrm{l})$ injected intradermally, on the dorsum of the hind paw. Mechanical nociceptive threshold was evaluated $30 \mathrm{~min}$ and $4 \mathrm{~h}$ after intradermal $\mathrm{PGE}_{2}$. In all groups, PGE ${ }_{2}$-induced hyperalgesia was measured 30 min after its injection. However, the prolongation of $\mathrm{PGE}_{2}$-induced hyperalgesia at the fourth hour was markedly attenuated in the groups treated with cordycepin, SU6656 + U0126, and the combination of all three inhibitors $\left(F_{(3,20)}=10.8, * * * p=0.0002\right.$, when the vehicle-treated group is compared with the inhibitors-treated groups at the fourth hour after intradermal PGE $;$ twoway repeated-measures ANOVA followed by Bonferroni post hoc test). $\boldsymbol{B}$, Four days after intrathecal treatment with vehicle or inhibitors, at which time the mechanical nociceptive threshold was not different from the pre-vehicle/inhibitor baseline $\left(t_{(5)}=1.2 ; p=0.27\right.$, for the vehicle-treated group, $t_{(5)}=0.72 ; p=0.51$, for the cordycepin-treated group, $t_{(5)}=0.44 ; p=0.68$, for the combination of Src and MAPK inhibitors-treated group, and $t_{(5)}=1.6 ; p=0.17$, for the group treated with the combination of all three inhibitors, when the mechanical nociceptive threshold is compared before and after intrathecal inhibitors; paired Student's $t$ test), $\mathrm{PGE}_{2}(100 \mathrm{ng} / 5 \mu \mathrm{l})$ was again injected. In the groups previously treated with intrathecal cordycepin, SU6656 + U0126 and the combination of all three inhibitors, prolongation of $\mathrm{PGE}_{2}$-induced hyperalgesia was markedly attenuated $\left(F_{(3,20)}=23.6\right.$, ****p $<0.0001$, when the hyperalgesia in the vehicle-treated and the inhibitors-treated groups is compared at the fourth hour after intradermal PGE ${ }_{2}$; two-way repeated-measures ANOVA followed by Bonferroni post hoc test). Similarly, $14 \mathrm{~d}(\boldsymbol{C})$ and $28 \mathrm{~d}(\boldsymbol{D})$ after intrathecal injection of vehicle, cordycepin, SU6656 + U0126, or the combination of all three inhibitors, when PGE $2(100 \mathrm{ng} / 5 \mu \mathrm{l})$ was again injected intradermally, the prolongation of $\mathrm{PGE}_{2}$-induced hyperalgesia was still attenuated in all three groups treated with the inhibitors $\left(14 \mathrm{~d}, \boldsymbol{C}: F_{(3,20)}=4.1, * p=0.02 ;\right.$ and $28 \mathrm{~d}, \boldsymbol{D}$ : $F_{(3,20)}=7.9$, $* * p=0.0011$, when the vehicle-treated group is compared with the inhibitors-treated groups at the fourth hour after intradermal PGE 2 ; two-way repeated-measures ANOVA followed by Bonferroni post hoc test). These findings support the suggestion that systemic fentanyl induces both Type I and Type II priming, in the peripheral terminal of the nociceptor ( $n=6$ paws 6 rats per group).

$p<0.0001$, when the combination of SU6656 + U0126-treated group is compared with the vehicle-treated and the cordycepintreated groups at the fourth hour after intrathecal $\mathrm{PGE}_{2}$; twoway ANOVA multiple comparations test; Fig. $2 A$ ). To verify whether intrathecal treatment with inhibitors permanently reversed priming induced by systemic fentanyl in the central terminal of the nociceptor, $\mathrm{PGE}_{2}$ (400 ng) was again injected $4 \mathrm{~d}$
(Fig. 2B), $14 \mathrm{~d}$ (Fig. 2C), and $28 \mathrm{~d}$ (Fig. 2D) after vehicle and inhibitors. The prolongation of $\mathrm{PGE}_{2}$-induced hyperalgesia was still inhibited in the group treated with the combination of SU6656 + U0126 but not in the vehicle-treated and cordycepintreated groups $\left(F_{(2,15)}=41.6, p<0.0001\right.$, when the combination of SU6656 + U0126-treated group was compared with the vehicle-treated and the cordycepin-treated groups at the fourth hour 

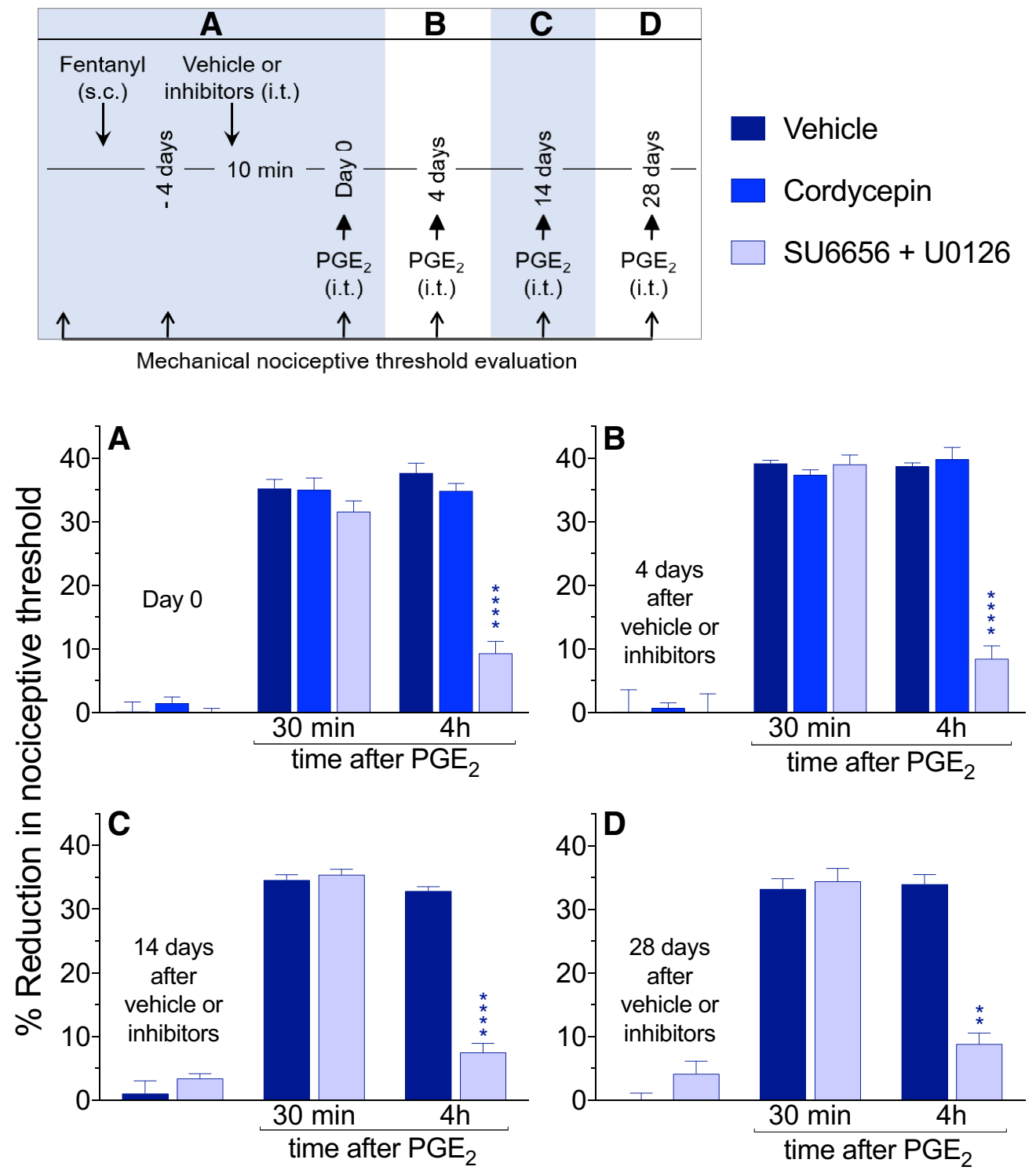

Figure 2. Systemic fentanyl induces Type II priming in nociceptor central terminals. $\boldsymbol{A}$, Male rats were treated with systemic fentanyl ( $30 \mu \mathrm{g} / \mathrm{kg}$, s.c.). Four days later, when mechanical nociceptive threshold was not different from pre-fentanyl baseline $\left(t_{(17)}=0.18, p=0.86\right.$ when the mechanical nociceptive threshold was compared before and $4 \mathrm{~d}$ after systemic fentanyl; paired Student's $t$ test), vehicle ( $2 \%$ DMSO in saline, $20 \mu \mathrm{l})$, cordycepin $(4 \mu \mathrm{g} / 10 \mu \mathrm{l})$, or the combination of Src inhibitor $(\mathrm{SU} 6656,10 \mu \mathrm{g} / 5 \mu \mathrm{l})$ and MAPK inhibitor $(\mathrm{U} 0126,10 \mu \mathrm{g} / 5 \mu \mathrm{l})$ were administered intrathecally followed, $10 \mathrm{~min}$ later, by $\mathrm{PGE}_{2}(400 \mathrm{ng} / 10 \mu \mathrm{l})$ administered at the same site, intrathecally. Mechanical nociceptive threshold was evaluated 30 min and $4 \mathrm{~h}$ after intrathecal PGE 2 . PGE 2 -induced hyperalgesia was present in all groups, 30 min after its injection. When the prolongation of $\mathrm{PGE}_{2}$-induced hyperalgesia was evaluated at the fourth hour after its injection, in the group treated with the combination of Src and MAPK inhibitors it was markedly attenuated $\left(F_{(2,15)}=47.9, * * * * p<0.0001\right.$, when the combination of Src and MAPK inhibitors-treated group is compared with the vehicle-and cordycepin-treated groups at the fourth hour after intrathecal PGE 2 ; two-way repeated-measures ANOVA followed by Bonferroni post hoc test); however, no attenuation was observed in the vehicle-treated and cordycepin-treated groups. $\boldsymbol{B}$, Four days after intrathecal vehicle and inhibitors, when the mechanical nociceptive threshold was not different from pre-vehicle/inhibitor baseline $\left(t_{(5)}=0.07 ; p=0.95\right.$, for the vehicle-treated group, $t_{(5)}=0.81 ; p=0.46$, for the cordycepin-treated group, and $t_{(5)}=0.08 ; p=0.94$, for the combination of Src and MAPK inhibitors-treated group, when the mechanical nociceptive threshold is compared before and after intrathecal inhibitors; paired Student's $t$ test), PGE 2 (400 ng/ $20 \mu \mathrm{l}$ ) was again injected intrathecally and mechanical nociceptive threshold evaluated 30 min and $4 \mathrm{~h}$ later. In the group treated with the combination of Src and MAPK inhibitors the prolongation of PGE $\mathrm{E}_{2}$-induced hyperalgesia was still attenuated $\left(F_{(2,15)}=41.6, * * * * p<0.0001\right.$, when the combination of Src and MAPK inhibitors-treated group was compared with the vehicletreated and cordycepin-treated groups, at the fourth hour after intrathecal $\mathrm{PGE}_{2}$; two-way repeated-measures ANOVA followed by Bonferroni post hoc test). To verify that the reversal of priming in the central terminal of the nociceptor was permanent, intrathecal $P \mathrm{PEE}_{2}$ was again injected $14 \mathrm{~d}(\boldsymbol{C})$ and $28 \mathrm{~d}(\boldsymbol{D})$ after intrathecal vehicle or inhibitors. Of note, the cordycepin-treated group was not tested at the next two time points, since it did not show any attenuation in the prolongation of $\mathrm{PGE}_{2}$-induced hyperalgesia in the previous experiments. $\boldsymbol{C}, \boldsymbol{D}$, In the group of rats treated with the combination of SrC and MAPK inhibitors, the prolongation of intrathecal $\mathrm{PGE}_{2}$-induced hyperalgesia was still markedly attenuated at $14 \mathrm{~d}\left(\boldsymbol{C} ; F_{(1,10)}=56.4, * * * * p<0.0001\right)$ and $28 \mathrm{~d}\left(\boldsymbol{D} ; F_{(1,10)}=14.3, * * p=0.004\right.$, when the vehicle-treated and the combination of Src and MAPK inhibitors-treated groups were compared at the fourth hour after intrathecal PGE ; two-way repeated-measures ANOVA followed by Bonferroni post hoc test) after intrathecal vehicle and inhibitors. These findings indicate that at the central terminal of the nociceptor systemic fentanyl induces Type II priming ( $n=6$ paws/ 6 rats per group).

after intrathecal $\mathrm{PGE}_{2}$; two-way ANOVA multiple comparations test; Fig. 2B). Since treatment with cordycepin did not affect the prolongation of $\mathrm{PGE}_{2}$-induced hyperalgesia in systemic fentanylprimed rats, this group was not tested at the follow-up time points. In the group of rats treated with the combination of SU6656 + U0126, the prolongation of $\mathrm{PGE}_{2}$-induced hyperalgesia was still inhibited at days 14 and 28 after its administration [14 d (Fig. 2C) $F_{(1,10)}=56.4, p<0.0001$; and $28 \mathrm{~d}$ (Fig. $2 D$ ) $F_{(1,10)}=14.3, p=0.0036$, when the vehicle-treated group is compared with the combination of SU6656 + U0126-treated group 


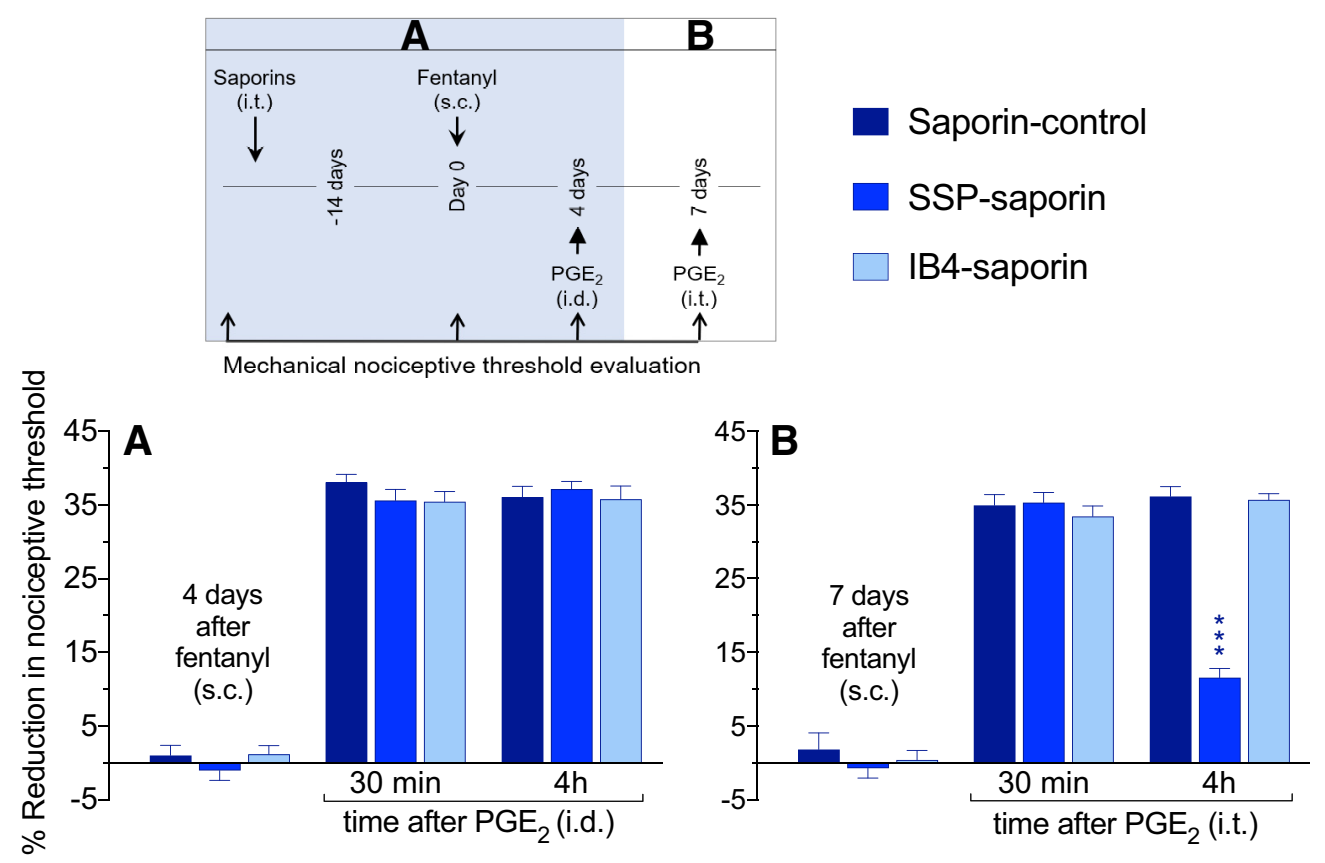

Figure 3. Role of IB4+ and IB4- nociceptors in priming induced at the peripheral and central nociceptor terminal by systemic fentanyl. Rats received an intrathecal injection of control saporin $(3.2 \mu \mathrm{g} / 20 \mu \mathrm{l})$, SSP-saporin $(100 \mathrm{ng} / 20 \mu \mathrm{l})$, or IB4-saporin $(3.2 \mu \mathrm{g} / 20 \mu \mathrm{ll})$. Fourteen days later, at which time the mechanical nociceptive threshold was not different from pre-saporin baselines $\left[t_{(5)}=0.59 ; p=0.58\right.$, for the saporin (control)-treated group, $t_{(5)}=1.3 ; p=0.24$, for the SSP-saporin-treated group, and $t_{(5)}=0.47 ; p=0.66$, for the IB4-saporin-treated group, when the mechanical nociceptive threshold is compared before and $14 \mathrm{~d}$ after treatments; paired Student's $t$ test], fentanyl $(30 \mu \mathrm{g} / \mathrm{kg})$ was injected subcutaneously. A, Four days later, at which time mechanical nociceptive threshold was not different from pre-fentanyl baseline $\left[t_{(5)}=0.25 ; p=0.81\right.$, for the saporin (control)-treated group, $t_{(5)}=0.52 ; p=0.62$, for the SSP-saporin-treated group, and $t_{(5)}=0.061 ; p=0.95$, for the IB4-saporin-treated group, when the mechanical nociceptive threshold was compared before and $4 \mathrm{~d}$ after systemic fentanyl; paired Student's $t$ test] $\mathrm{PGE}_{2}(100 \mathrm{ng} / 5 \mu \mathrm{l})$ was injected intradermally and mechanical nociceptive threshold evaluated $30 \mathrm{~min}$ and $4 \mathrm{~h}$ later. Hyperalgesia was present in all saporin-treated groups measured 30 min after its injection. Also, prolonged hyperalgesia induced by intradermal $\mathrm{PGE}_{2}$ was present in all groups treated with saporins $\left(F_{(2,15)}=0.69, p=0.52\right.$, when all saporin-treated groups are compared at the fourth hour after intradermal $\mathrm{PGE}_{2}$; two-way repeated-measures ANOVA followed by Bonferroni post hoc test), indicating that in the peripheral terminal of the nociceptor systemic fentanyl does not require IB4+ and SP peptidergic nociceptors to develop priming. $\boldsymbol{B}$, Seven days after systemic fentanyl and $3 \mathrm{~d}$ after intradermal $\mathrm{PGE}_{2}$, rats were tested for priming in the central terminal of the nociceptor. PGE $(400 \mathrm{ng} / 20 \mu \mathrm{l})$ was injected intrathecally and mechanical nociceptive threshold evaluated $30 \mathrm{~min}$ and $4 \mathrm{~h}$ later. Intrathecal PGE ${ }_{2}$-induced hyperalgesia in all saporin-treated groups, measured $30 \mathrm{~min}$ after its administration. However, the prolongation of $\mathrm{PGE}_{2}$-induced hyperalgesia at the fourth hour was markedly attenuated in the group treated with SSP-saporin, but not in the saporin-control-treated and IB4-saporin-treated groups $\left[F_{(2,15)}=16.0, * * * p=0.0002\right.$, when the SSP-saporin-treated group is compared with the saporin (control)-treated and the IB4-saporin-treated groups at the fourth hour after intrathecal $\mathrm{PGE}_{2}$; two-way repeated-measures ANOVA followed by Bonferroni post hoc test]. These findings support the suggestion that at the central terminal, systemic fentanyl requires IB4- peptidergic nociceptors to induce priming ( $n=6$ paws/6 rats per group).

Table 1. Effect of PGE 2 on small DRG neurons of different IB4-binding classes from control animals

\begin{tabular}{|c|c|c|c|}
\hline & Strongly IB4+ & Weakly IB4+ & IB4- \\
\hline Number of cells tested with $\mathrm{PGE}_{2}$ & 10 & 14 & 9 \\
\hline$\%$ of neurons responsive to $\mathrm{PGE}_{2}$ [number of responsive cells] & $\begin{array}{l}60 \% \\
{[6 \text { cells }]}\end{array}$ & $\begin{array}{l}71 \% \\
\quad[10 \text { cells }]\end{array}$ & $\begin{array}{l}67 \% \\
{[6 \text { cells }]}\end{array}$ \\
\hline$\%$ reduction in rheobase induced by $100 \mathrm{~nm} \mathrm{PGE}_{2}$ & $23 \pm 3$ & $24 \pm 4$ & $27 \pm 7$ \\
\hline $\begin{array}{l}\text { Baseline rheobase, } \mathrm{pA} \\
\quad \text { (including neurons not tested with } \mathrm{PGE}_{2} \text { ) }\end{array}$ & $\begin{array}{l}384 \pm 56 \\
\quad(n=20)\end{array}$ & $\begin{array}{l}313 \pm 45 \\
\quad(n=23)\end{array}$ & $\begin{array}{l}294 \pm 47 \\
(n=20)\end{array}$ \\
\hline
\end{tabular}

at the fourth hour after intrathecal $\mathrm{PGE}_{2}$; two-way ANOVA multiple comparations test]. These data support the suggestion that systemic fentanyl induces Type II but not Type I priming in nociceptor central terminals, which is in accordance with our previous findings (Araldi et al., 2018c), while Type I priming only occurs at the peripheral terminal.

\section{Involvement of peptidergic nociceptors in priming at the central terminal}

Maintenance of Type I and Type II priming can occur in different classes of nociceptors. For example, Type I, induced by inflammatory mediators, occurs in IB4+ nonpeptidergic nociceptors (Joseph and Levine, 2010), while Type II priming, induced by intradermal DAMGO, was prevented by intrathecal administration of SSP-saporin (Araldi et al., 2018b), known to disrupt signaling pathway of peptidergic (mostly IB4-) nociceptors (Seki et al., 2005). In the present experiments, we evaluated the role of these two nociceptor populations in priming induced by systemic fentanyl, in the peripheral and central nociceptor terminals. Saporin-control, IB4saporin [destroys IB4+ (mostly nonpeptidergic) nociceptors], or SSP-saporin was injected intrathecally and, $14 \mathrm{~d}$ later, systemic fentanyl $(30 \mu \mathrm{g} / \mathrm{kg})$ was administered subcutaneously. Four days later, $\mathrm{PGE}_{2}$ was injected intradermally and the mechanical nociceptive threshold evaluated $30 \mathrm{~min}$ and $4 \mathrm{~h}$ after its injection. Prolongation of $\mathrm{PGE}_{2}$-induced hyperalgesia was present in all saporin-treated groups $\left[F_{(2,15)}=0.69, p=0.52\right.$, when the control (saporin), the SSPsaporin-treated and the IB4-saporin-treated groups are compared at the fourth hour after intradermal $\mathrm{PGE}_{2}$; two-way repeated-measures 
A
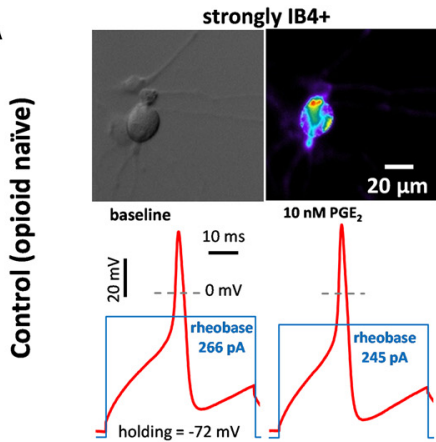

B

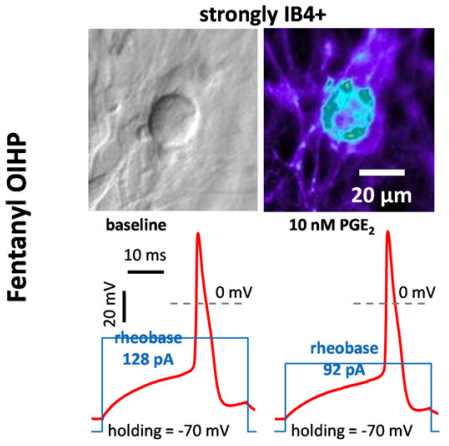

C

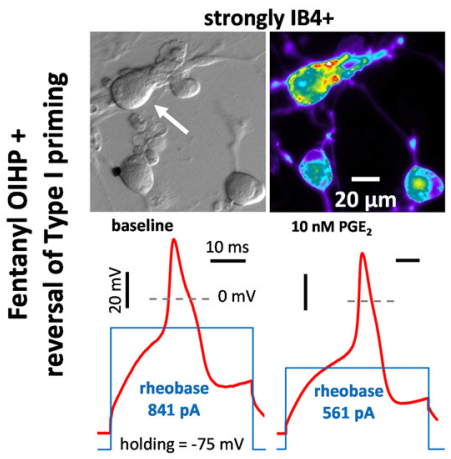

D

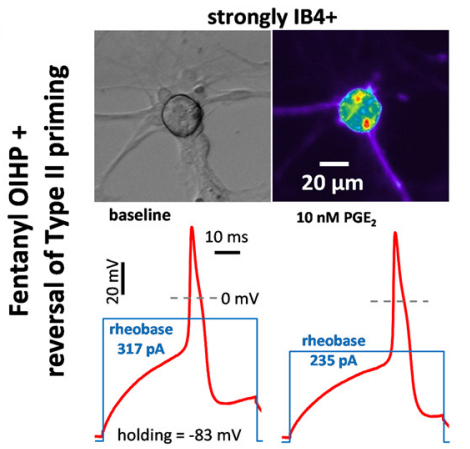

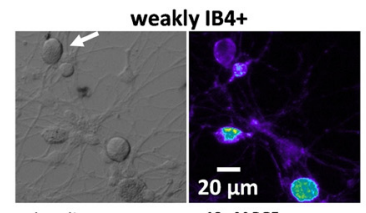
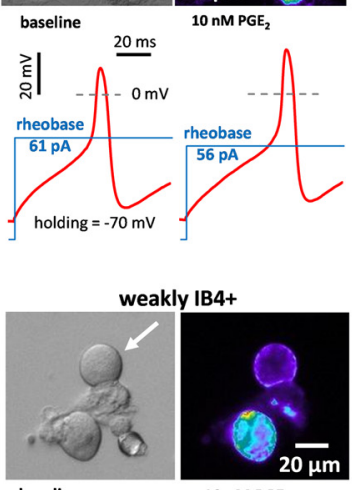

baseline $10 \mathrm{nM} \mathrm{PGE}_{2}$

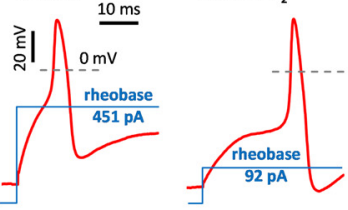

weakly IB4+
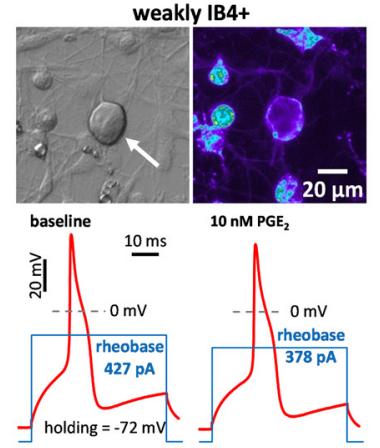

weakly IB4+
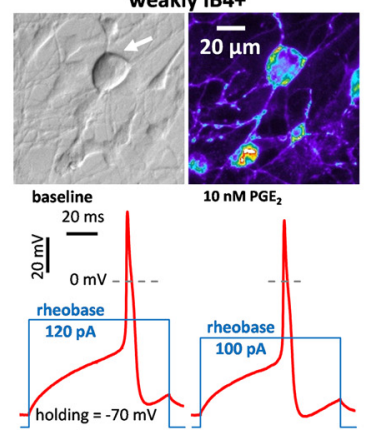
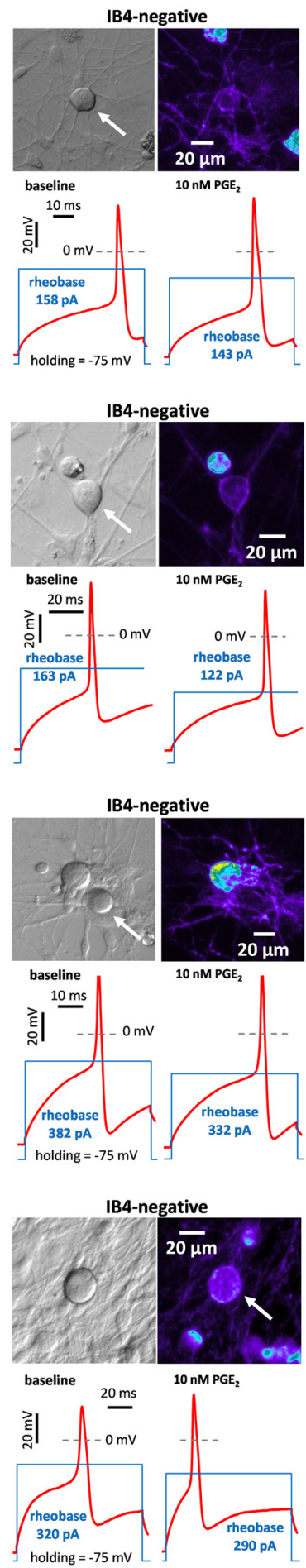

Figure 4. Illustration of $P G E_{2}$-induced sensitization in small DRG neurons in vitro. Rows (A-D) represent groups of DRG neurons cultured from rats with different conditions: control (opioid naive, $\boldsymbol{A}$ ), fentanyl-primed $(\boldsymbol{B})$, and fentanyl-primed with reversal of Type I $(\boldsymbol{C}$ ) and of Type II (D) priming, as defined in Figures 5-7. Strongly IB4+, weakly IB4+, and IB4- small DRG neurons, sensitized by $\mathrm{PGE}_{2}$, are depicted in each group. For each depicted neuron, its image in transmitted light (DIC contrast; upper left), fluorescent image of IB4-labeling (pseudocolor; upper right), and two electrophysiological recordings (below) are shown. The recordings, made in current clamp mode, show APs (red line) induced by current step of rheobase magnitude, before (lower left) and $10 \mathrm{~min}$ after (lower right) administration of $\mathrm{PGE}_{2}(10 \mathrm{~nm})$. Stimulation profile is shown as blue line, in the same scale in left and right recordings (the scale differs between neurons). Note, the reduction in rheobase after administration of $\mathrm{PGE}_{2}$, which was used to quantify magnitude of sensitization (further analyzed in Figs. 5-7), is larger in fentanyl-primed group for each IB4-binding status $(\boldsymbol{B})$ compared with opioid naive group $(\boldsymbol{A})$; attenuation of the sensitizing effect of $\mathrm{PGE}_{2}$ was observed in both reversal groups $(\boldsymbol{C}, \boldsymbol{D})$ compared with the primed group $(\boldsymbol{B})$, in weakly IB4+ and IB4-, but not in strongly IB4+ neurons.

ANOVA; Fig. $3 A$ ], indicating that fentanyl-induced priming in the nociceptor peripheral terminal is not dependent on SP peptidergic or IB4+ nociceptors, compatible with the role of a different class of nociceptors (Cavanaugh et al., 2011; Araldi et al., 2018c). Seven days after systemic fentanyl and $3 \mathrm{~d}$ after intradermal $\mathrm{PGE}_{2}$, priming was tested in the central terminal. Rats received $\mathrm{PGE}_{2}(400 \mathrm{ng})$ intrathecally and mechanical nociceptive threshold was evaluated $30 \mathrm{~min}$ and $4 \mathrm{~h}$ later. In the group treated with SSP-saporin, but not 
A
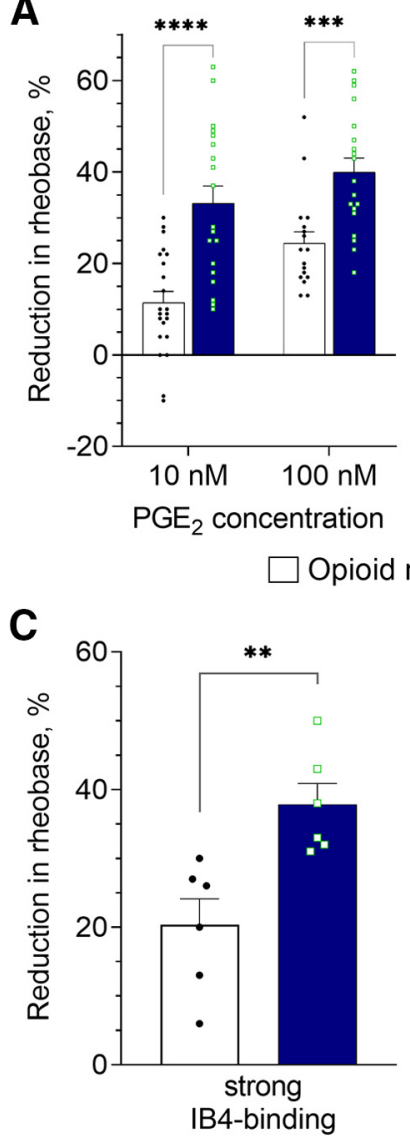

B

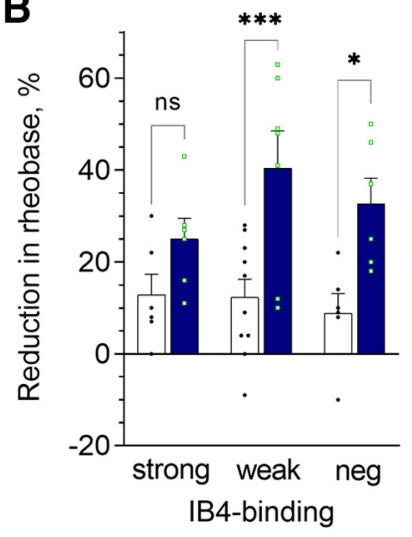

Primed in vivo

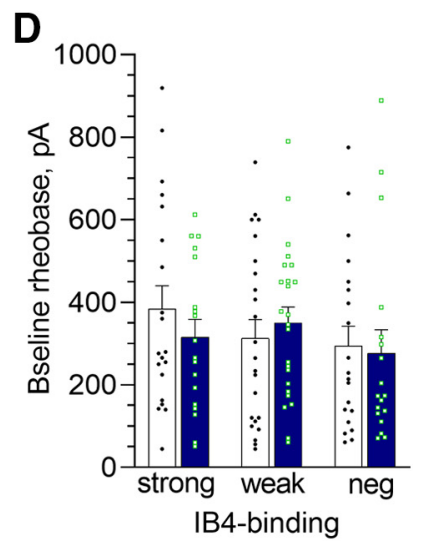

Figure 5. Fentanyl-induced priming in vivo is associated with enhanced $\mathrm{PGE}_{2}$-induced sensitization of small DRG neurons, in vitro. Rats were primed by the systemic administration of fentanyl $(30 \mu \mathrm{g} / \mathrm{kg}$, s.c.) $8 \mathrm{~d}$ before preparing neuronal cultures, to parallel our in vivo protocol: $4 \mathrm{~d}$ before (injection of fentanyl) and $4 \mathrm{~d}$ after administering of vehicle or reversal agents. Patch-clamp electrophysiology recordings were made in small-diameter DRG neurons from fentanyl-primed and control (opioid naive) groups (depicted in all panels by the white and dark blue bars, correspondingly), after $24 \mathrm{~h}$ in culture. In $\boldsymbol{A}-\boldsymbol{C}$, bars show pooled magnitudes of decrease in rheobase, relative to preadministration baseline (measured before the first application of $P \mathrm{PG}_{2}$ ), and 5 min after application (10 and $100 \mathrm{~nm}$ ); $10 \mathrm{~nm} \mathrm{PGE}_{2}$ was applied first, and then, 10 min later, its concentration was increased to $100 \mathrm{~nm}$ (cumulative concentration dependence). Symbols show individual values. Only those neurons with a change in rheobase of not $<10 \%$, for the higher or lower concentration, were considered for analysis. Some neurons were not tested with the higher concentration because of loss of the patch (but only used if they showed at least 10\% reduction in rheobase for the lower concentration), therefore, regular ANOVA was used for analysis. $A$, Reduction of rheobase in response to 10 and $100 \mathrm{nM} \mathrm{PGE}_{2}$, analyzed regardless of IB4-binding status. In DRG neurons from primed rats the effect of both concentrations of $\mathrm{PGE}_{2}$ was significantly greater than in controls [two-way ANOVA: effect of $\mathrm{PGE}_{2}$ concentration, $p=0.0015, F_{(1,73)}=10.8$; effect of condition: $p<0.0001, F_{(1,73)}=38.2$; not significant (ns) interaction: $p=0.32, F_{(1,73)}=1.0$; Holm-Sidak's post hoc: $t_{(73)}=5.3$, ****adjusted $p<0.0001$ for $10 \mathrm{~nm} ; t_{(73)}=$ 3.6, ***adjusted $p=0.0007$ for $100 \mathrm{~nm}$ ]. Number of cells in control group: $n=22$ for $10 \mathrm{nM}$ and $n=17$ for $100 \mathrm{~nm}$; in primed group: $n=19$ for both 10 and $100 \mathrm{~nm}$. $\boldsymbol{B}$, Reduction of rheobase in response to $\mathrm{PGE}_{2}(10 \mathrm{~nm})$, in neurons separated by IB4-binding intensity into: strongly IB4+ ("strong"), weakly IB4+ ("weak"), and IB4- classes ("neg"). Effect of priming was statistically significant (two-way ANOVA: effect of condition $F_{(1,35)}=23.0, p<0.0001$; effect of IB4-binding status $F_{(2,35)}=1.1, p=0.34$; interaction $\left.F_{(2,35)}=1.2, p=0.33\right)$. Holm-Sidak's post hoc test revealed a statistically significant increase in the effect of $\mathrm{PGE}_{2}$ in weakly IB4+ $\left(t_{(35)}=4.1\right.$, ***adjusted $\left.p=0.0008\right)$ and IB4- $\left(t_{(35)}=2.9\right.$, *adjusted $\left.p=0.011\right)$ classes, indicating a leftward shift in the concentration-response curve for $\mathrm{PGE}_{2}$ in these neurons. In strongly IB4+ neurons, the effect of priming was not statistically significant $\left(t_{(35)}=1.5\right.$, adjusted $p=0.14$ ). Number of cells (strong/weak/neg) in control group: $6 / 10 / 6$, in primed group: $6 / 7 / 6$. C, Reduction of rheobase in response to $100 \mathrm{~nm} \mathrm{PGE}_{2}$ in strongly IB4+ neurons from the primed group of rats was significantly enhanced compared with the control group ( $n=6$ per group; two-tailed unpaired Student's $t$ test: $t_{(10)}=3.6, * * p=0.005$ ), indicating a different change in this neuronal population associated with in vivo priming. $\boldsymbol{D}$, Baseline rheobase (before administration of $\mathrm{PGE}_{2}$ ) in three neuronal classes with different IB4-binding status. $\mathrm{PGE}_{2}$-sensitive and $\mathrm{PGE}_{2}$-insensitive neurons were included in the analysis of baseline rheobase. Differences between primed and control groups as well as between classes were not statistically significant [two-way ANOVA: effect of IB4-binding status, not significant (ns), $p=0.92, F_{(2,117)}=0.40$; effect of condition: $n s, p=0.68, F_{(1,117)}=0.17$; interaction: $n s, p=0.53, F_{(2,117)}=0.64$ ]. Number of cells (strong/weak/neg) in control group: 20/23/20, in primed group: 18/24/18.

the saporin (control)-treated and IB4-saporin-treated groups, prolongation of $\mathrm{PGE}_{2}$-induced hyperalgesia was markedly attenuated $\left[F_{(2,15)}=16.0, p=0.0002\right.$, when the saporin (control), the SSP-saporin-treated and the IB4-saporin-treated groups are compared at the fourth hour after intrathecal $\mathrm{PGE}_{2}$; two-way repeated-measures ANOVA; Fig. $3 B]$, indicating that priming induced by systemic fentanyl, in the central terminal of the nociceptor, is dependent on peptidergic nociceptors. These data support the suggestion that more than one population of nociceptors is involved in OIHP induced by systemic fentanyl.

\section{Enhanced $\mathrm{PGE}_{2}$-induced sensitization of sensory neurons} cultured from fentanyl-primed rats To further understand the populations of nociceptors in which priming occurs, we translated our in vivo to an in vitro priming model by examining the effect of systemic fentanyl on $\mathrm{PGE}_{2}$-induced sensitization of cultured DRG neurons. Since it is not practical to hold cells clamped for 4 $\mathrm{h}$, to reveal priming, we relied on another in vivo feature of hyperalgesic priming, a more than one order magnitude leftward shift (to lower values) for the dose dependence of $\mathrm{PGE}_{2}$-induced hyperalgesia (Parada et al., 2005). Since only $\sim 60 \%$ of cultured DRG neurons are responsive to $\mathrm{PGE}_{2}$ (Gold et al., 1996b), it would not be possible to distinguish between responsive and nonresponsive neurons by their response to a low concentration of $\mathrm{PGE}_{2}$; response to a higher concentration is required. Therefore, we chose two $\mathrm{PGE}_{2}$ concentrations, 10 and $100 \mathrm{~nm}$, to examine our hypothesis that priming induces a leftward shift of the dose-response curve in primed DRG neurons.

In cultures of DRG neurons derived from opioid naive animals, corresponding magnitudes of sensitization were $11 \pm 2 \%(n=22)$ for 10 nM $\mathrm{PGE}_{2}$ and $24 \pm 2 \%(n=17)$ for 100 nм PGE $; 67 \%$ of small DRG neurons (soma diameter $<30 \mu \mathrm{m}$; see Materials and Methods) examined (22 out of 33) were responsive to $\mathrm{PGE}_{2}$. Average baseline rheobase of examined neurons was $310 \pm 41 \mathrm{pA}$ $(n=33)$. In DRG neurons from control animals, no significant difference was found between mean rheobase values of small DRG neurons responsive $(314 \pm 55 \mathrm{pA})$ and nonresponsive $(282 \pm 81 \mathrm{pA})$ to $\mathrm{PGE}_{2}$ (unpaired $t$ test, $t_{(31)}=0.3$ ). Considering that DRG neurons in different IB4-binding classes have different electrophysiological properties (Stucky and Lewin, 1999) and are differentially 
affected by exposure to fentanyl (Khomula et al., 2019), we analyzed their response to $\mathrm{PGE}_{2}$, separately (Table 1). Fractions of neurons responsive to $\mathrm{PGE}_{2}$ and magnitude of sensitization by $10 \mathrm{~nm} \mathrm{PGE}_{2}$ were similar under control conditions; ANOVA did not reveal a significant difference between baseline rheobase $\left(p=0.42, F_{(2,60)}=0.89\right)$.

In cultured small-diameter DRG neurons derived from animals primed with fentanyl in vivo (primed group) reduction of rheobase induced by both concentrations of $\mathrm{PGE}_{2}$ (10 and $100 \mathrm{~nm}$ ) was significantly greater than in neurons from control animals (two-way ANOVA: effect of condition: $p<0.0001, F_{(1,73)}=38.2$; Holm-Sidak's post hoc: $t_{(73)}=5.3$, adjusted $p<0.0001$ for 10 $\mathrm{nM} ; t_{(73)}=3.6$, adjusted $p=0.0007$ for 100 nм; Figs. $4 A, B, 5 A)$. And, when neurons were separated according to their IB4-binding status, and analyzed, the effect of $10 \mathrm{nM}$ $\mathrm{PGE}_{2}$ (Fig. 5B), our primary endpoint, a significant effect of priming was confirmed (two-way ANOVA: effect of condition $\left.F_{(1,35)}=23.0, p<0.0001\right)$. Holm-Sidak's post hoc test revealed a significant increase in the effect of $\mathrm{PGE}_{2}$ in weakly IB4 $+\left(t_{(35)}=\right.$ 4.1 , adjusted $p=0.0008)$ and IB4- $\left(t_{(35)}=\right.$ 2.9 , adjusted $p=0.011$ ) classes. In strongly IB4+ neurons, the difference between primed and control groups was not statistically significant for $10 \mathrm{nM} \mathrm{PGE}_{2}\left(t_{(35)}=1.5\right.$, adjusted $p=0.14)$. However, for these neurons we found a significant increase in sensitization by the higher concentration (100 $\mathrm{nM}$ ) of $\mathrm{PGE}_{2}$ (two-tailed unpaired Student's $t$ test: $t_{(10)}=3.6, p=0.005$; Fig. $5 C$ ).

Of note, we did not see a significant effect of priming on rheobase of neurons of any IB4-binding status [two-way ANOVA: effect of IB4-binding status, not significant (ns), $p=0.92, F_{(2,117)}=0.40$; effect of condition: ns, $p=0.68, F_{(1,117)}=0.17$; interaction: ns, $p=0.53, F_{(2,117)}=0.64$; Fig. $\left.5 D\right]$, or when the three classes were combined (control vs priming, two-tailed unpaired Student's $t$ test: $\left.t_{(122)}=0.34, p=0.73\right)$. This is in agreement with the results of our current (Fig. 1) and previous (Ferrari et al., 2013; Hendrich et al., 2013; Araldi et al., 2015, 2018c; Khomula et al., 2019) behavioral studies, which demonstrated no effect of priming on baseline mechanical nociceptive threshold.

These findings confirm our initial hypothesis that priming-like neuroplasticity could be observed in vitro, in nociceptors cultured from primed rats, and identify nociceptor populations in which this occurs. While all three nociceptor populations were affected by fentanyl, leftward shift in dose dependence of $\mathrm{PGE}_{2}$-induced sensitization was only observed in weakly IB4+ and IB4-
A

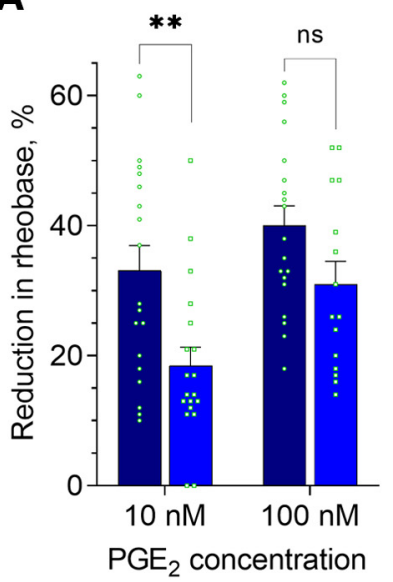

Primed in vivo

C

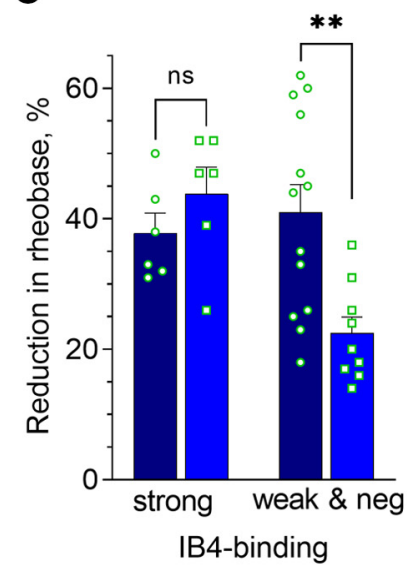

B

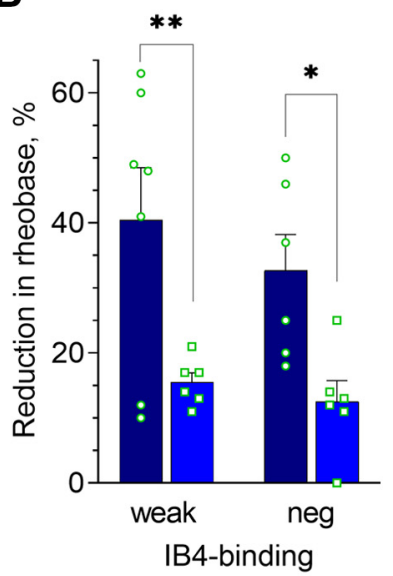

Cordycepin in vivo
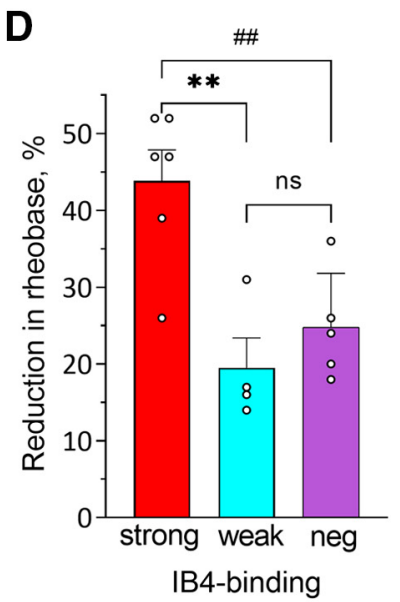

Figure 6. Effect of in vivo treatment of fentanyl-primed rats with the reversal agent for Type I priming on $\mathrm{PGE}_{2^{-}}$ induced sensitization of small DRG neurons. Rats were primed by the systemic administration of fentanyl $(30 \mu \mathrm{g} / \mathrm{kg}, \mathrm{s.c.}$.) $8 \mathrm{~d}$ before preparing neuronal cultures ( $4 \mathrm{~d}$ before intrathecal cordycepin, followed by an additional $4 \mathrm{~d}$ before culture preparation). Recordings were made in small-diameter DRG neurons from fentanyl-primed animals either treated (reversal group) or not treated (primed group) with cordycepin (depicted in $\mathbf{A}-\mathbf{C}$ by the blue and dark blue bars, correspondingly) after $24 \mathrm{~h}$ in culture. In $\boldsymbol{A}-\boldsymbol{D}$, bars show pooled magnitudes of decrease in rheobase, relative to baseline, after $\mathrm{PGE}_{2}$ application (10 and $100 \mathrm{~nm}$ ), measured and analyzed in the same way as described in Figure 5 and Materials and Methods. Symbols show individual values. In $\boldsymbol{A}-\boldsymbol{C}$, values for primed group were repeated from Figure $5 A-C$ for the purpose of comparison. $\boldsymbol{A}$, Reduction of rheobase in response to 10 and $100 \mathrm{nM} \mathrm{PGE}$, analyzed regardless of IB4-binding status. In neurons from primed rats the effect of $10 \mathrm{~nm}$ but not $100 \mathrm{nM} \mathrm{PGE}_{2}$ was significantly greater than in the reversal group [two-way ANOVA; effect of condition: $F_{(1,68)}=12.5, p=0.0007$; Holm-Sidak's post hoc: $t_{(68)}=3.2$, **adjusted $p=0.004$ for $10 \mathrm{~nm} ; t_{(68)}=1.8$, adjusted $p=0.07$, not significant (ns), for $100 \mathrm{~nm}$ ]. Number of cells in primed group: $n=19$ for both 10 and $100 \mathrm{~nm}$; in reversal group: $n=19$ for $10 \mathrm{~nm}$ and $n=15$ for $100 \mathrm{~nm}$. $\boldsymbol{B}$, Reduction of rheobase in response to $10 \mathrm{~nm}$ PGE 2 in weakly IB4 + ("weak") and IB4- classes ("neg") neurons. Attenuation of PGE 2 -induced sensitization after in vivo cordycepin was statistically significant in both neuronal populations (two-way ANOVA: effect of condition $F_{(1,21)}=16.3, p=0.0006$; Holm-Sidak's post hoc: $t_{(21)}=3.2$, **adjusted $p=0.008$ for weakly IB4+; $t_{(21)}=2.5$, *adjusted $p=0.02$ for IB4-). Number of cells (weak/neg) in reversal group: 6/6, in primed group: 7/6. C, Reduction of rheobase in response to $100 \mathrm{~nm}$ PGE $_{2}$ in strongly IB4 + ("strong") and merged weakly IB4+ and IB4- ("weak and neg") neurons from primed and reversal groups. Tw0-way ANOVA revealed statistically significant interaction $\left(F_{(1,30)}=8.5\right.$, $p=0.007$ ), indicating differential effects on the three different neuronal classes. Indeed, statistically significant attenuation in reversal compared with primed group occurred in weakly IB4+ and IB4- but not in strongly IB4+ neurons (Holm-Sidak's post hoc: $t_{(30)}=0.9$, adjusted $p=0.38$ for strong, not significant (ns); $t_{(30)}=3.7$, **adjusted $p=0.002$ for weak and neg). Number of cells (strong/weak and neg): $6 / 13$ in primed group, $6 / 9$ in reversal group. D, Reduction of rheobase in response to $100 \mathrm{~nm} \mathrm{PGE}_{2}$ in strongly IB4+ (strong), weakly IB4+ (weak), and IB4- (neg) neurons from reversal group. Values in strongly IB4+ class were significantly greater than in weakly IB4+ and IB4- neurons [one-way ANOVA: $F_{(2,12)}=11.8$, ** $p=0.002$; Tukey's post hoc: $q_{(12)}=6.3$, adjusted $p=0.002$ for strongly IB4+ vs weakly $\mathrm{IB} 4+; q_{(12)}=5.2$, \#\#adjusted $p=0.008$ for strongly IB4+ vs IB4-; $q_{(12)}=1.3$, adjusted $p=0.63$, not significant (ns), for weakly IB4+ vs IB4-]. Number of cells: 6 strong, 4 weak, 5 neg. 
A

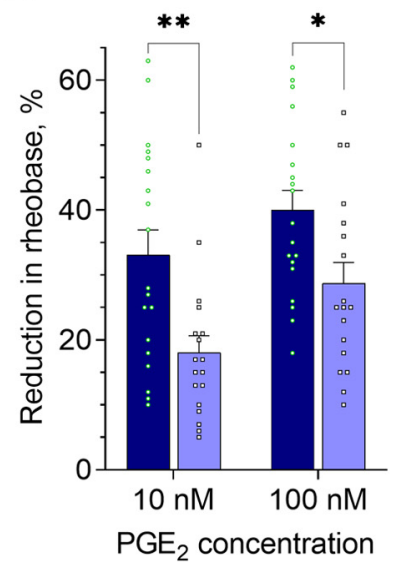

$\square$ Primed in vivo

C

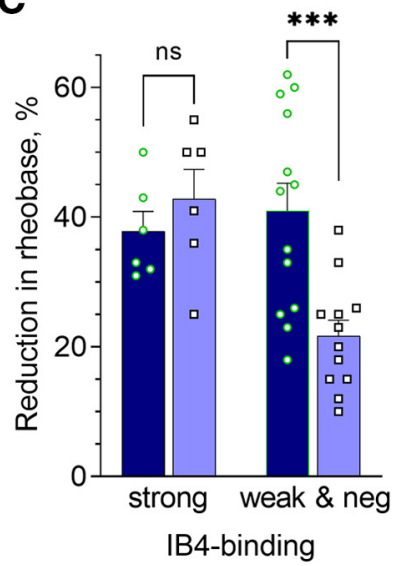

B

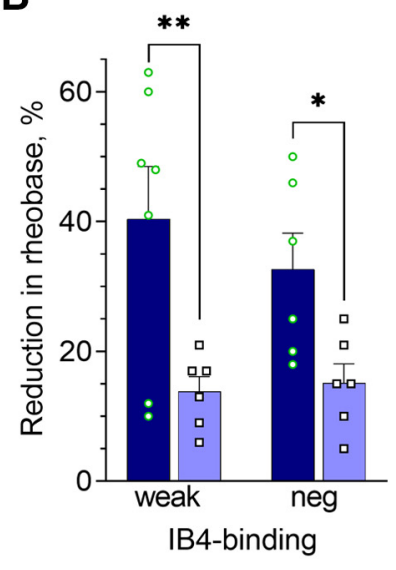

SU6656 + U0126 in vivo

D

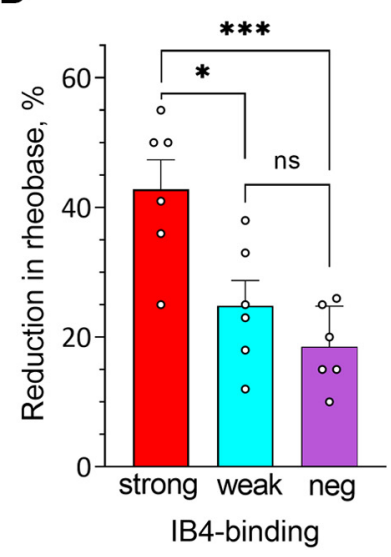

Figure 7. Effect of in vivo treatment of fentanyl-primed rats with reversal agents for Type II priming on $\mathrm{PGE}_{2}$-induced sensitization of small DRG neurons. Rats were primed by the systemic administration of fentanyl $(30 \mu \mathrm{g} / \mathrm{kg}$, s.c.) $8 \mathrm{~d}$ before preparing neuronal cultures ( $4 \mathrm{~d}$ before reversal agents, followed by $4 \mathrm{~d}$ before culture preparation). Recordings were made in small-diameter DRG neurons from fentanyl-primed animals treated intrathecally with the combination of a Src and MAPK inhibitor (SU6656 + U0126; Type II reversal group; light blue bars) and not treated (primed group; dark blue bars). In $\boldsymbol{A}-\boldsymbol{D}$, bars show pooled magnitudes of decrease in rheobase after $\mathrm{PGE}_{2}$ application (10 and/or $100 \mathrm{~nm}$ ), relative to baseline (measured before the first application), measured and analyzed in the same way as described in Figure 6, while symbols show individual values. In $\boldsymbol{A}-$ $\boldsymbol{C}$, values for primed group were repeated from Figure $5 A-C$ for the purpose of comparison. $\boldsymbol{A}$, Reduction of rheobase in response to 10 and $100 \mathrm{nM} \mathrm{PGE}_{2}$, analyzed regardless of IB4-binding status. In the primed group the effect of 10 and $100 \mathrm{~nm} P G E_{2}$ was significantly greater than in the Type II reversal group (two-way ANOVA; effect of condition: $F_{(1,70)}=16.6, p=0.0001$; HolmSidak's post hoc: $t_{(70)}=3.3$, **adjusted $p=0.003$ for $10 \mathrm{~nm} ; t_{(70)}=2.5$, *adjusted $p=0.02$ for $100 \mathrm{~nm}$ ). Number of cells in primed group: $n=19$ for both 10 and $100 \mathrm{~nm}$; in Type II reversal group: $n=18$ for both 10 and $100 \mathrm{~nm}$. $\boldsymbol{B}$, Reduction of rheobase

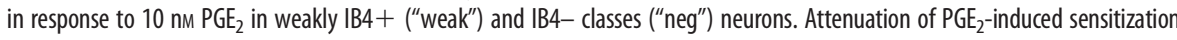
after in vivo administration of the combination of a Src and MAPK inhibitor was statistically significant in both neuronal subpopulations (two-way ANOVA: effect of condition $F_{(1,21)}=15.5, p=0.0008$; Holm-Sidak's post hoc: $t_{(21)}=3.4$, **adjusted $p=0.005$ for weakly IB4+; $t_{(21)}=2.2$, *adjusted $p=0.04$ for IB4-). Number of cells (weak/neg) in Type II reversal group: 6/6, in primed group: 7/6. C, Reduction of rheobase in response to $100 \mathrm{nM} \mathrm{PGE}_{2}$ in strongly IB4+ ("strong") and merged weakly IB4+ and IB4- ("weak and neg") neurons from primed and reversal groups. Two-way ANOVA revealed statistically significant interaction $\left(F_{(1,33)}=8.8, p=0.006\right)$, indicating differential effects on different neuronal classes. Indeed, statistically significant attenuation in reversal group compared with the primed group occurred in weakly IB4 + and IB4- but not in strongly IB4 + neurons [HolmSidak's post hoc: $t_{(33)}=0.74$, adjusted $p=0.46$ for strong, not significant (ns); $t_{(33)}=4.1$, ***adjusted $p=0.0005$ for weak and neg]. Number of cells (strong/weak and neg): $6 / 13$ in primed group, 6/12 in Type II reversal group. $\boldsymbol{D}$, Reduction of rheobase in response to $100 \mathrm{nM} \mathrm{PGE} 2$ in strongly IB4+ (strong), weakly IB4+ (weak), and IB4- (neg) neurons from reversal group. Reduction of rheobase in the strongly IB4+ class were significantly greater than in weakly IB4+ and IB4- neurons [one-way ANOVA: $F_{(2,15)}=11.2, p=0.0010$; Tukey's post hoc: $q_{(15)}=4.8$, *adjusted $p=0.011$ for strongly IB4+ vs weakly IB4+; $q_{(15)}=$ 6.5 , **adjusted $p=0.0010$ for strongly IB4 + vs IB4-; $q_{(15)}=1.7$, adjusted $p=0.48$, not significant (ns), for weakly IB4+ vs IB4-]. Number of cells: 6 strong, 6 weak, 6 neg.

populations of putative nociceptors. However, enhanced sensitization by the high dose of $\mathrm{PGE}_{2}$ was found in strongly IB4+ nociceptors. Together, our behavioral and in vitro findings support the suggestion that fentanyl-induced priming develops in the nociceptor.
Intrathecal cordycepin attenuates priming-induced enhancement of $\mathrm{PGE}_{2}$ sensitization of nociceptors, in vitro

Using our in vitro model of fentanylinduced priming, we determined whether administration of cordycepin, which partially reversed priming in vivo, has a similar effect on priminglike neuroplasticity in cultured DRG neurons. We prepared cultures of DRG neurons derived from animals that were primed in vivo with fentanyl and $4 \mathrm{~d}$ later received intrathecal cordycepin (cordycepin group), used in our behavior experiments to attenuate Type I priming (Fig. 1). DRG neuron cultures were prepared $4 \mathrm{~d}$ after administering cordycepin, a time at which attenuation of priming was observed in behavioral experiments (Fig. 1). Small-diameter DRG neurons cultured from the cordycepin-treated group received $\mathrm{PGE}_{2}$ (10 nM) and then, 10 min later, $\mathrm{PGE}_{2} 100 \mathrm{~nm}$, and magnitude of the reduction in rheobase induced was compared with that in DRG neurons from primed rats (Figs. 4B,C, 6).

First, we compared the effects of $\mathrm{PGE}_{2}, 10$ and $100 \mathrm{~nm}$, on small DRG neurons, regardless of IB4-binding status (Fig. 6A). We found a significant attenuation of the sensitizing effect of $\mathrm{PGE}_{2}$ in the cordycepin-treated group compared with the primed group, for $10 \mathrm{~nm}$ but not for $100 \mathrm{~nm} \mathrm{PGE}_{2}$ (twoway ANOVA; effect of condition: $F_{(1,68)}=12.5, p=0.0007$; Holm-Sidak's post hoc: $t_{(68)}=3.2$, adjusted $p=0.004$ for $10 \mathrm{nM} ; t_{(68)}=1.8$, adjusted $p=0.07$, for $100 \mathrm{~nm})$. This finding supports the suggestion that in vivo administration of cordycepin attenuates priming in nociceptors, in vitro, similar to our in vivo observation.

To assess possible IB4-binding status-specific changes induced by in vivo administration of cordycepin, we took into account our finding of an enhanced effect of $10 \mathrm{~nm} \mathrm{PGE}_{2}$ on weakly IB4+ and IB4- populations, and the enhanced effect of only $100 \mathrm{~nm}$ $\mathrm{PGE}_{2}$ on strongly IB4+ neurons. We found significant attenuation of the sensitizing effect of $10 \mathrm{nM} \mathrm{PGE}_{2}$ in weakly IB4+ and IB4- neurons after cordycepin was administered in vivo to primed animals (two-way ANOVA; effect of condition: $F_{(1,21)}=16.3$, $p=0.0006$; Holm-Sidak's post hoc: $t_{(21)}=3.2$, adjusted $p=0.008$ for weakly IB4+; $t_{(21)}=2.5$, adjusted $p=0.02$ for IB4-; Fig. $6 B$ ). In contrast, the enhanced sensitizing effect of $100 \mathrm{nM} \mathrm{PGE}_{2}$ in 
strongly IB4+ neurons was not significantly different between neurons from primed and cordycepin-treated primed rats (twoway ANOVA: statistically significant effect of interaction: $F_{(1,30)}$ $=8.5, p=0.007$; Holm-Sidak's post hoc: $t_{(30)}=0.9$, adjusted $p=0.38$ for strongly IB4 $+; t_{(30)}=3.7$, adjusted $p=0.002$ for weakly IB4+ and IB4- combined; Fig. 6C). In strongly IB4+ neurons, from cordycepin treated rats, the sensitizing effect of $100 \mathrm{nM} \mathrm{PGE}_{2}$ was significantly greater than in weakly IB4+ and IB4- neurons (one-way ANOVA: $F_{(2,12)}=11.8, p=0.002$; Tukey's post hoc: $q_{(12)}=6.3$, adjusted $p=0.002$ for strongly IB4+ vs weakly IB4+; $q_{(12)}=5.2$, adjusted $p=0.008$ for strongly IB4 + vs IB4-; $q_{(12)}=1.3$, adjusted $p=0.63$ for weakly IB4+ vs IB4-; Fig. 6D). These results support the suggestion that maintenance mechanisms of enhanced sensitization by $\mathrm{PGE}_{2}$ are dependent on Type I priming in weakly IB4+ and IB4- nociceptor populations.

\section{Intrathecal Src plus MAPK inhibitors attenuates priming-induced enhancement of $\mathrm{PGE}_{2}$ sensitization of nociceptors, in vitro}

Using our in vitro model of fentanyl-induced priming, we next determined whether in vivo administration of agents that reverse Type II priming (Fig. 1) also attenuates enhanced $\mathrm{PGE}_{2}$-induced sensitization in DRG neurons cultured from fentanyl-treated animals, and which nociceptor populations were affected. Animals were primed with fentanyl, in vivo, and $4 \mathrm{~d}$ later received the combination of Src and MAPK inhibitors (intrathecally; Fig. 1A). DRGs were harvested for culturing $4 \mathrm{~d}$ later. Reduction of rheobase induced by 10 and $100 \mathrm{nM} \mathrm{PGE}_{2}$ in smalldiameter DRG neurons from these cultures were compared with corresponding values in cultures from the primed group of animals (Figs. $4 B, D, 7$ ). We found a significant attenuation of the sensitizing effect of $\mathrm{PGE}_{2}$ in this reversal group compared with the primed group, when neurons were analyzed regardless of IB4-binding status (two-way ANOVA; effect of condition: $F_{(1,70)}=16.6, p=0.0001$; Holm-Sidak's post hoc: $t_{(70)}=3.3$, adjusted $p=0.003$ for $10 \mathrm{~nm} ; t_{(70)}=2.5$, adjusted $p=0.02$ for 100 nM; Fig. $7 A$ ). When IB4-binding status was considered, we found significant attenuation of the sensitizing effect of $\mathrm{PGE}_{2}(10 \mathrm{nM})$, in weakly IB4+ and IB4- neurons (two-way ANOVA; effect of condition: $F_{(1,21)}=15.5, p=0.0008$; Holm-Sidak's post hoc: $t_{(21)}=3.4$, adjusted $p=0.005$ for weakly IB4+; $t_{(21)}=2.2$, adjusted $p=0.04$ for IB4-; Fig. $7 B$ ). The sensitizing effect of $\mathrm{PGE}_{2}(100 \mathrm{nM})$ in strongly IB4+ neurons was not significantly different between reversal and primed groups (two-way ANOVA; statistically significant effect of interaction: $F_{(1,33)}=8.8, p=0.006$; Holm-Sidak's post hoc: $t_{(33)}=0.74$, adjusted $p=0.46$ for strongly IB4 + ; $t_{(33)}=4.1$, adjusted $p=0.0005$ for weakly IB4 + and IB4combined; Fig. 7C). However, the sensitizing effect of $100 \mathrm{nM}$ $\mathrm{PGE}_{2}$ in strongly $\mathrm{IB} 4+$ neurons was significantly greater than in weakly IB4+ and IB4- neurons (one-way ANOVA: $F_{(2,15)}=11.2$, $p=0.0010$; Tukey's post hoc: $q_{(15)}=4.8$, adjusted $p=0.011$ for strongly IB4+ vs weakly IB4+; $q_{(15)}=6.5$, adjusted $p=0.0010$ for strongly IB4+ vs IB4-; $q_{(15)}=1.7$, adjusted $p=0.48$ for weakly IB4+ vs IB4-; Fig. 7D). These results, along with the results of the previous section (Fig. 6), confirm a significant functional difference between strongly IB4+ nociceptors versus weakly IB4 + and IB4- nociceptors in how they were affected by systemic fentanyl, in vivo. While in both reversal groups, $\mathrm{PGE}_{2}$-induced sensitization in strongly IB4+ neurons remained unattenuated, compared with the primed group, in weakly IB4+ and IB4- neurons, it was significantly attenuated. Overall, the in vitro effect of combined in vivo inhibition of Src and MAPK on all three classes was

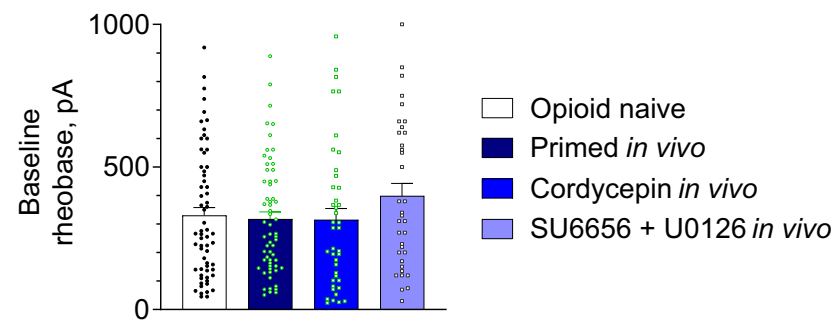

Figure 8. Priming by fentanyl in vivo as well as in vivo reversal of priming does not alter baseline rheobase of small DRG neurons in vitro. Bars show pooled baseline rheobase (before administration of $\mathrm{PGE}_{2}$ ) in the whole neuronal population (regardless of IB4-binding status) in control, primed, and two reversal groups, as defined in Figures 5-7. Symbols show individual values. $P \mathrm{PEE}_{2}$-sensitive and $\mathrm{PGE}_{2}$-insensitive neurons were included in the analysis. Difference between groups was not statistically significant (one-way ANOVA: $p=0.26$, $\left.F_{(3,196)}=1.33\right)$. Number of cells: 63 in control, 61 in primed, 41 in Type I, and 35 in Type II reversal groups.

qualitatively similar to that found for in vivo cordycepin (Fig. 6). Of note, enhanced sensitization by $\mathrm{PGE}_{2}$ in both weakly IB4+ and IB4- nociceptor populations shared maintenance mechanisms with both Type I and Type II priming.

Our analysis did not reveal a significant difference in baseline rheobase between DRG neurons from control, primed groups of rats, and groups of primed rats treated with reversal agents for Type I and Type II priming, correspondingly (one-way ANOVA: $p=0.26, F_{(3,196)}=1.33$; Fig. 8 ). Thus, baseline excitability of nociceptors is not affected by priming or by reversal of priming, in agreement with our current (Fig. 1) and previous behavioral studies (Aley et al., 2000; Parada et al., 2005; Reichling and Levine, 2009; Ferrari et al., 2013; Hendrich et al., 2013; Araldi et al., 2015, 2018c, 2019; Khomula et al., 2017), where baseline mechanical nociceptive threshold remained unchanged.

In summary, we have demonstrated, in vivo, the existence of long-lasting nociceptor neuroplasticity, induced by systemic administration of an analgesic dose of fentanyl. This neuroplasticity, which involves changes in nociceptor function, is responsible for both hyperalgesic priming and, as previously shown, for OIH (Khomula et al., 2017). Here, for the first time, we have created an in vitro model for studying OIHP. Using this model, we provide evidence for specific changes in electrophysiological properties of nociceptors, in their response to $\mathrm{PGE}_{2}$, which correlates with the presence of hyperalgesic priming in vivo and reversal (partial permanent attenuation) by cordycepin or the combination of Src and MAPK inhibitors. The combination of behavioral and in vitro cellular approaches allowed us to provide evidence of different roles for classes of nociceptors in hyperalgesic priming induced in vivo by systemic fentanyl. Additionally, our in vitro results identified a novel form of neuroplasticity in strongly IB4+ nociceptors, characterized by increased change in rheobase induced by the high but not low concentration of $\mathrm{PGE}_{2}$, which is not reversed by either cordycepin or the combination of Src and MAPK inhibitors. Studies are ongoing to elucidate the in vivo correlate of this novel form of nociceptor neuroplasticity. We suggest that the residual $\mathrm{PGE}_{2}$-induced hyperalgesia $(\sim 50 \%)$, which was still present at the peripheral nociceptor terminal at the fourth hour, in rats treated with inhibitors of both Type I and Type II priming (Fig. 1), is mediated by neuroplasticity in strongly IB4+ nociceptors.

\section{Discussion}

Opioid analgesics, especially of the fentanyl class, can produce a hypersensitivity to noxious stimuli $(\mathrm{OIH})$ and long-lasting pain 
exacerbation (chronification; Zylicz and Twycross, 2008; Silverman, 2009; Yi and Pryzbylkowski, 2015). Since the action of MOR agonists on nociceptors plays an important role in their pronociceptive effects (Scherrer et al., 2009; Corder et al., 2017; Streicher and Bilsky, 2017), we focused on cellular mechanisms of OIHP, using in vitro patch-clamp electrophysiology.

Three forms of OIHP have been reported. Type I is reversed by cordycepin (Ferrari et al., 2013, 2019; Araldi et al., 2018c), Type II by the combination of a Src and MAPK inhibitor (Araldi et al., 2017a, 2018c), and a third type, produced by biased MOR agonists, is neither Type I nor Type II (Araldi et al., 2018a). In the case of fentanyl, different nociceptor populations and distinct intracellular mechanisms are involved in OIHP induced in the setting of different routes of administration and doses (i.e., subanalgesic and analgesic; Araldi et al., 2018c). Our present in vivo findings show that an analgesic dose of fentanyl induces priming in the peripheral terminal of the nociceptor, sharing maintenance mechanisms with both Type I and Type II priming.

Consistent with our in vivo findings, we observed enhanced $\mathrm{PGE}_{2}$-induced sensitization (reduction of rheobase) in small-diameter DRG neurons cultured from fentanyl-primed rats, confirming our hypothesis that priming-like neuroplasticity can be observed in vitro. Enhanced sensitization by the lower concentration of $\mathrm{PGE}_{2}$, which was our primary endpoint, was only observed in weakly IB4+ and IB4- neurons. In contrast, in strongly IB4+ neurons we found a significant increase in sensitization by the higher but not the lower concentration of $\mathrm{PGE}_{2}$. Of note, we did not observe an effect of priming on pre- $\mathrm{PGE}_{2}$ rheobase, paralleling the lack of change in baseline nociceptive threshold in primed animals, in behavioral studies (Parada et al., 2005; Araldi et al., 2018c; Ferrari et al., 2019). Our finding of priming-like neuroplasticity in cultured DRG neurons, which have lost their terminals in peripheral tissues and spinal dorsal horn, during culture preparation, support the suggestion that the priming state in nociceptors also exists in the soma.

A significant attenuation of the enhanced sensitizing effect of the low concentration (10 nM) of $\mathrm{PGE}_{2}$ was observed in weakly IB4+ and IB4- DRG neurons (both peptidergic) cultured from rats whose fentanyl-induced priming was reversed in vivo by agents that reverse Type I (cordycepin) or Type II (the combination of a Src and a MAPK inhibitors) priming. These findings support the suggestion that both Type I and Type II priming develop, in the same or different nociceptor populations, identified in vitro as weakly IB4+ and IB4- (peptidergic) nociceptors. However, underlying intracellular mechanisms, allowing coexistence of both Type I and Type II priming in the same neuron, still need to be investigated. One might suggest a convergent signaling event, downstream, affected by Type I and Type II reversal agents. For instance, protein translation in DRG neurons requires ERK signaling, and Src activation and PKA/PKC activation may also lead to ERK activation (Hu and Gereau, 2003; Kawasaki et al., 2004; Uttam et al., 2018), supporting the suggestion that Type II reversal agents might also inhibit protein translation (required for Type I priming) downstream of ERK signaling. However, Type II priming at the central terminal was not sensitive to cordycepin (Fig. 2; Araldi et al., 2018c). Similarly, Type I priming is insensitive to agents that reverse Type II priming (Araldi et al., 2018c; Ferrari et al., 2019). Together, these findings support the suggestion that there is no overlap between mechanisms of Type I and Type II priming.

Alternatively, it is possible that different neuronal subpopulations, within weakly IB4+ and IB4- peptidergic nociceptors mediate Type I and Type II priming. In this case, however, one would expect an additive attenuating effect of reversal agents of Type I and Type II priming in vivo (as they would act on different neurons), which we did not observe (Fig. 1). The prominent attenuating effect of SSP-saporin on fentanyl-induced priming, only at the nociceptor central terminal (Fig. 3), indicates that different populations of nociceptors mediate priming, and in particular Type II priming, at the central and peripheral terminal. The fact that OIHP, in the nociceptor peripheral terminal, was not affected by either IB4-saporin or SSP-saporin treatment could be attributed to the involvement of a different class of nociceptors, negative for both nonpeptidergic and peptidergic markers, as suggested in our previous study in which intrathecal fentanylinduced priming in the nociceptor peripheral terminal was not prevented by treatment with IB4-saporin or SSP-saporin (Araldi et al., 2018c). Of note, nonpeptidergic IB4- neurons account for $\sim 20 \%$ of TRPV $1^{+}$neurons, as shown in mice (Cavanaugh et al., 2011).

The enhanced sensitizing effect of the higher concentration of $\mathrm{PGE}_{2}$, in strongly IB4+ (non-peptidergic) neurons was not attenuated by drugs that reverse Type I or Type II priming, identifying a novel form of neuroplasticity in these nociceptors. It is possible that neuroplasticity in this class of nociceptors contributes to the remaining $\mathrm{PGE}_{2}$-induced hyperalgesia, at the fourth hour, in rats treated with a combination of drugs that reverse both Type I and Type II priming that did not attenuate priming any more than inhibition of either Type I or Type II priming alone.

Although we use only mechanical stimulation to reveal enhanced and prolonged hyperalgesia, we do not expect that priming has selectivity to stimulus modality. Indeed, our in vitro findings suggest that priming is associated with enhanced reduction of threshold for electrical excitability in response to $\mathrm{PGE}_{2}$. Thus, any depolarizing stimulus capable of activating a primed nociceptor would require lower stimulus magnitude to trigger AP generation after sensitization.

Observed changes in rheobase implicate changes in ion channel function. It is very likely that the function of channels mediating the effects of $\mathrm{PGE}_{2}$ are affected, including voltage-gated sodium, potassium and calcium channels (Gold et al., 1996a, 1998; Kopp and Cicha, 1999; Gu et al., 2008; Fan et al., 2011; for review, see Kawabata, 2011). We do not, however, think that priming directly affects properties of ion channels involved in AP generation, rather it alters the $\mathrm{PGE}_{2}$ signaling pathway (Aley et al., 2000; Khasar et al., 2008; for review, see Reichling and Levine, 2009; Reichling et al., 2013).

Once sensitized, any part of a primed nociceptor may contribute to a prolongation of hyperalgesia and in this way contribute to pain chronification. For instance, tissue damage, like a surgical incision or wound, is associated with production of sensitizing agents, resulting in hyperalgesia. In the case of priming, when nociceptors remain sensitized for a much longer time after administration of sensitizing agents, pain would be expected to be prolonged as well. Increased and prolonged nociceptor activity in the presence of a stimulus that leads to activation of the nociceptor likely will facilitate central sensitization. Of note, since priming by itself does not alter pain sensitivity, it is unlikely to lead to central sensitization.

Along with central sensitization, hyperalgesic priming is recognized as an integral part of the "pain memory" paradigm (Ji et al., 2003; Price and Inyang, 2015) and serves to illuminate a critical role of the nociceptor in pain chronification. Studies have 
demonstrated the progressive nature of chronic pain (Price and Inyang, 2015), as well as OIH, which has been tightly linked to OIHP in our studies (Khomula et al., 2019). Use of opioids for analgesia in a clinical setting, from the perspective of our OIHP model may be viewed as the triggering event for induction of a pain memory, thus providing important clinical parallels that can help explain mechanisms and suggest potential pathways to resolution of neuroplasticity that drives chronicity.

In conclusion, our in vitro results indicate that fentanyl induces neuroplasticity in nociceptors of all three IB4-binding categories; neuroplasticity in weakly IB4+ and IB4- (peptidergic) nociceptors likely contributes to Type I and Type II OIHP in vivo, which differs from our previous finding for $\mathrm{OIH}$ induced by fentanyl, where only a role of weakly IB4+ nociceptors was observed (Khomula et al., 2019). Of note, strongly IB4+ nociceptors, which develop a novel type of neuroplasticity in fentanyl-primed animals, also revealed robust fentanyl-induced sensitization in cultures from opioid naive animals, which does not account for fentanyl induced $\mathrm{OIH}$, since it did not become greater in cultures from primed animals. In contrast, weakly IB4+ and IB4- nociceptors were sensitized by fentanyl in cultures from in vivo primed animals, sensitization that was reversed by cordycepin, but only in weakly IB4+ neurons (Khomula et al., 2019). On the other hand, their enhanced $\mathrm{PGE}_{2}$-induced sensitization, attributed to priming, was attenuated by cordycepin and the combination of Src and MAPK inhibitors, in both peptidergic classes. Together, these findings indicate that fentanyl produces different effects in peptidergic and non-peptidergic neuronal classes; they also reveal differences between neuroplasticity in weakly IB4+ and IB4- nociceptors, dissected by the effect of intrathecal cordycepin on their sensitization by fentanyl, in vitro.

\section{References}

Aley KO, Messing RO, Mochly-Rosen D, Levine JD (2000) Chronic hypersensitivity for inflammatory nociceptor sensitization mediated by the epsilon isozyme of protein kinase C. J Neurosci 20:4680-4685.

Araldi D, Ferrari LF, Levine JD (2015) Repeated mu-opioid exposure induces a novel form of the hyperalgesic priming model for transition to chronic pain. J Neurosci 35:12502-12517.

Araldi D, Ferrari LF, Levine JD (2016a) Adenosine-A1 receptor agonist induced hyperalgesic priming type II. Pain 157:698-709.

Araldi D, Ferrari LF, Levine JD (2016b) Gi-protein-coupled 5-HT1B/D receptor agonist sumatriptan induces type I hyperalgesic priming. Pain 157:1773-1782.

Araldi D, Ferrari LF, Levine JD (2017a) Hyperalgesic priming (type II) induced by repeated opioid exposure: maintenance mechanisms. Pain 158:1204-1216.

Araldi D, Ferrari LF, Green P, Levine JD (2017b) Marked sexual dimorphism in 5-HT1 receptors mediating pronociceptive effects of sumatriptan. Neuroscience 344:394-405.

Araldi D, Ferrari LF, Levine JD (2018a) Mu-opioid receptor (MOR) biased agonists induce biphasic dose-dependent hyperalgesia and analgesia, and hyperalgesic priming in the rat. Neuroscience 394:60-71.

Araldi D, Ferrari LF, Levine JD (2018b) Role of GPCR (mu-opioid)-receptor tyrosine kinase (epidermal growth factor) crosstalk in opioid-induced hyperalgesic priming (type II). Pain 159:864-875.

Araldi D, Khomula EV, Ferrari LF, Levine JD (2018c) Fentanyl induces rapid onset hyperalgesic priming: type I at peripheral and type II at central nociceptor terminals. J Neurosci 38:2226-2245.

Araldi D, Bogen O, Green PG, Levine JD (2019) Role of nociceptor toll-like receptor 4 (TLR4) in opioid-induced hyperalgesia and hyperalgesic priming. J Neurosci 39:6414-6424.

Ballantyne JC (2015) Opioid therapy in chronic pain. Phys Med Rehabil Clin N Am 26:201-218.

Bennett DL, Averill S, Clary DO, Priestley JV, McMahon SB (1996) Postnatal changes in the expression of the trkA high-affinity NGF receptor in primary sensory neurons. Eur J Neurosci 8:2204-2208.
Bennett DL, Michael GJ, Ramachandran N, Munson JB, Averill S, Yan Q, McMahon SB, Priestley JV (1998) A distinct subgroup of small DRG cells express GDNF receptor components and GDNF is protective for these neurons after nerve injury. J Neurosci 18:3059-3072.

Bicket MC, Brat GA, Hutfless S, Wu CL, Nesbit SA, Alexander GC (2019) Optimizing opioid prescribing and pain treatment for surgery: review and conceptual framework. Am J Health Syst Pharm 76:1403-1412.

Cavanaugh DJ, Chesler AT, Bráz JM, Shah NM, Julius D, Basbaum AI (2011) Restriction of transient receptor potential vanilloid-1 to the peptidergic subset of primary afferent neurons follows its developmental downregulation in nonpeptidergic neurons. J Neurosci 31:10119-10127.

Chang L, Ye F, Luo Q, Wang Z, Wang Y, Xia Z, Shu H (2018) Effects of three forms of local anesthesia on perioperative fentanyl-induced hyperalgesia. Biosci Trends 12:177-184.

Cheung CW, Qiu Q, Choi SW, Moore B, Goucke R, Irwin M (2014) Chronic opioid therapy for chronic non-cancer pain: a review and comparison of treatment guidelines. Pain Physician 17:401-414.

Chia YY, Liu K, Wang JJ, Kuo MC, Ho ST (1999) Intraoperative high dose fentanyl induces postoperative fentanyl tolerance. Can J Anesth 46:872877.

Choi JI, Koehrn FJ, Sorkin LS (2012) Carrageenan induced phosphorylation of Akt is dependent on neurokinin-1 expressing neurons in the superficial dorsal horn. Mol Pain 8:4.

Chu LF, Clark DJ, Angst MS (2006) Opioid tolerance and hyperalgesia in chronic pain patients after one month of oral morphine therapy: a preliminary prospective study. J Pain 7:43-48.

Cohen LB, Keynes RD, Hille B (1968) Light scattering and birefringence changes during nerve activity. Nature 218:438-441.

Corder G, Tawfik VL, Wang D, Sypek EI, Low SA, Dickinson JR, Sotoudeh C, Clark JD, Barres BA, Bohlen CJ, Scherrer G (2017) Loss of $\mu$ opioid receptor signaling in nociceptors, but not microglia, abrogates morphine tolerance without disrupting analgesia. Nat Med 23:164-173.

De Felice M, Porreca F (2009) Opiate-induced persistent pronociceptive trigeminal neural adaptations: potential relevance to opiate-induced medication overuse headache. Cephalalgia 29:1277-1284.

Fan F, Ma A, Guan Y, Huo J, Hu Z, Tian H, Chen L, Zhu H, Fan L (2011) Effect of PGE2 on DA tone by EP4 modulating Kv channels with different oxygen tension between preterm and term. Int J Cardiol 147:58-65.

Fang X, Djouhri L, McMullan S, Berry C, Waxman SG, Okuse K, Lawson SN (2006) Intense isolectin-B4 binding in rat dorsal root ganglion neurons distinguishes $\mathrm{C}$-fiber nociceptors with broad action potentials and high Nav1.9 expression. J Neurosci 26:7281-7292.

Ferrari LF, Levine JD (2015) Plasma membrane mechanisms in a preclinical rat model of chronic pain. J Pain 16:60-66.

Ferrari LF, Bogen O, Chu C, Levine JD (2013) Peripheral administration of translation inhibitors reverses increased hyperalgesia in a model of chronic pain in the rat. J Pain 14:731-738.

Ferrari LF, Bogen O, Reichling DB, Levine JD (2015) Accounting for the delay in the transition from acute to chronic pain: axonal and nuclear mechanisms. J Neurosci 35:495-507.

Ferrari LF, Khomula EV, Araldi D, Levine JD (2016) Marked sexual dimorphism in the role of the ryanodine receptor in a model of pain chronification in the rat. Sci Rep 6:31221.

Ferrari LF, Khomula EV, Araldi D, Levine JD (2018) CD44 signaling mediates high molecular weight hyaluronan-induced antihyperalgesia. J Neurosci 38:308-321.

Ferrari LF, Araldi D, Bogen O, Green PG, Levine JD (2019) Systemic morphine produces dose-dependent nociceptor-mediated biphasic changes in nociceptive threshold and neuroplasticity. Neuroscience 398:64-75.

Gold MS, Shuster MJ, Levine JD (1996a) Role of a Ca(2+)-dependent slow afterhyperpolarization in prostaglandin E2-induced sensitization of cultured rat sensory neurons. Neurosci Lett 205:161-164.

Gold MS, Dastmalchi S, Levine JD (1996b) Co-expression of nociceptor properties in dorsal root ganglion neurons from the adult rat in vitro. Neuroscience 71:265-275.

Gold MS, Reichling DB, Shuster MJ, Levine JD (1996c) Hyperalgesic agents increase a tetrodotoxin-resistant $\mathrm{Na}+$ current in nociceptors. Proc Natl Acad Sci USA 93:1108-1112.

Gold MS, Levine JD, Correa AM (1998) Modulation of TTX-R INa by PKC and PKA and their role in PGE2-induced sensitization of rat sensory neurons in vitro. J Neurosci 18:10345-10355. 
Gu R, Jin Y, Zhai Y, Yang L, Zhang C, Li W, Wang L, Kong S, Zhang Y, Yang B, Wang WH (2008) PGE2 inhibits basolateral 50 pS potassium channels in the thick ascending limb of the rat kidney. Kidney Int 74 : 478-485.

Harper AA, Lawson SN (1985) Conduction velocity is related to morphological cell type in rat dorsal root ganglion neurones. J Physiol 359:31-46.

Hendrich J, Alvarez P, Joseph EK, Chen X, Bogen O, Levine JD (2013) Electrophysiological correlates of hyperalgesic priming in vitro and in vivo. Pain 154:2207-2215.

Hu HJ, Gereau RW 4th (2003) ERK integrates PKA and PKC signaling in superficial dorsal horn neurons. II. Modulation of neuronal excitability. J Neurophysiol 90:1680-1688.

Hwang SJ, Burette A, Valtschanoff JG (2003) VR1-positive primary afferents contact NK1-positive spinoparabrachial neurons. J Comp Neurol 460:255-265.

Ji RR, Kohno T, Moore KA, Woolf CJ (2003) Central sensitization and LTP: do pain and memory share similar mechanisms? Trends Neurosci 26: 696-705.

Joseph EK, Levine JD (2010) Hyperalgesic priming is restricted to isolectin B4-positive nociceptors. Neuroscience 169:431-435.

Joseph EK, Chen X, Bogen O, Levine JD (2008) Oxaliplatin acts on IB4-positive nociceptors to induce an oxidative stress-dependent acute painful peripheral neuropathy. J Pain 9:463-472.

Joseph EK, Reichling DB, Levine JD (2010) Shared mechanisms for opioid tolerance and a transition to chronic pain. J Neurosci 30:4660-4666.

Kashiba H, Hyon B, Senba E (1998) Glial cell line-derived neurotrophic factor and nerve growth factor receptor mRNAs are expressed in distinct subgroups of dorsal root ganglion neurons and are differentially regulated by peripheral axotomy in the rat. Neurosci Lett 252:107-110.

Kashiba H, Uchida Y, Senba E (2001) Difference in binding by isolectin B4 to trkA and c-ret mRNA-expressing neurons in rat sensory ganglia. Brain Res Mol Brain Res 95:18-26.

Kawabata A (2011) Prostaglandin E2 and pain-an update. Biol Pharm Bull 34:1170-1173.

Kawasaki Y, Kohno T, Zhuang ZY, Brenner GJ, Wang H, Van Der Meer C, Befort K, Woolf CJ, Ji RR (2004) Ionotropic and metabotropic receptors, protein kinase A, protein kinase $\mathrm{C}$, and Src contribute to C-fiber-induced ERK activation and cAMP response element-binding protein phosphorylation in dorsal horn neurons, leading to central sensitization. J Neurosci 24:8310-8321.

Khasabov SG, Rogers SD, Ghilardi JR, Peters CM, Mantyh PW, Simone DA (2002) Spinal neurons that possess the substance P receptor are required for the development of central sensitization. J Neurosci 22:9086-9098.

Khasar SG, Burkham J, Dina OA, Brown AS, Bogen O, Alessandri-Haber N, Green PG, Reichling DB, Levine JD (2008) Stress induces a switch of intracellular signaling in sensory neurons in a model of generalized pain. J Neurosci 28:5721-5730

Khomula EV, Viatchenko-Karpinski VY, Borisyuk AL, Duzhyy DE, Belan PV, Voitenko NV (2013) Specific functioning of Cav3.2 T-type calcium and TRPV1 channels under different types of STZ-diabetic neuropathy. Biochim Biophys Acta 1832:636-649.

Khomula EV, Ferrari LF, Araldi D, Levine JD (2017) Sexual dimorphism in a reciprocal interaction of ryanodine and IP3 receptors in the induction of hyperalgesic priming. J Neurosci 37:2032-2044.

Khomula EV, Araldi D, Levine JD (2019) In vitro nociceptor neuroplasticity associated with in vivo opioid-induced hyperalgesia. J Neurosci 39:70617073.

Kopp UC, Cicha MZ (1999) PGE2 increases substance P release from renal pelvic sensory nerves via activation of N-type calcium channels. Am J Physiol 276:R1241-R1248.

Kras JV, Weisshaar CL, Pall PS, Winkelstein BA (2015) Pain from intra-articular NGF or joint injury in the rat requires contributions from peptidergic joint afferents. Neurosci Lett 604:193-198.

Landowne D (1993) Measuring nerve excitation with polarized light. Jpn J Physiol 43:S7-S11.

Lyons PJ, Rivosecchi RM, Nery JP, Kane-Gill SL (2015) Fentanyl-induced hyperalgesia in acute pain management. J Pain Palliat Care Pharmacother 29:153-160.

Manchikanti L, Helm S, Fellows B, Janata JW, Pampati V, Grider JS, Boswell MV (2012) Opioid epidemic in the United States. Pain Physician 15:ES9ES38.
Mercadante S, Arcuri E, Santoni A (2019) Opioid-induced tolerance and hyperalgesia. CNS Drugs 33:943-955.

Mestre C, Pélissier T, Fialip J, Wilcox G, Eschalier A (1994) A method to perform direct transcutaneous intrathecal injection in rats. J Pharmacol Toxicol Methods 32:197-200.

Molliver DC, Wright DE, Leitner ML, Parsadanian AS, Doster K, Wen D, Yan Q, Snider WD (1997) IB4-binding DRG neurons switch from NGF to GDNF dependence in early postnatal life. Neuron 19:849-861.

Nishiguchi J, Sasaki K, Seki S, Chancellor MB, Erickson KA, de Groat WC, Kumon H, Yoshimura N (2004) Effects of isolectin B4-conjugated saporin, a targeting cytotoxin, on bladder overactivity induced by bladder irritation. Eur J Neurosci 20:474-482.

Ossipov MH, Lai J, King T, Vanderah TW, Porreca F (2005) Underlying mechanisms of pronociceptive consequences of prolonged morphine exposure. Biopolymers 80:319-324.

Parada CA, Yeh JJ, Reichling DB, Levine JD (2003) Transient attenuation of protein kinase Cepsilon can terminate a chronic hyperalgesic state in the rat. Neuroscience 120:219-226.

Parada CA, Reichling DB, Levine JD (2005) Chronic hyperalgesic priming in the rat involves a novel interaction between cAMP and PKCepsilon second messenger pathways. Pain 113:185-190.

Petruska JC, Napaporn J, Johnson RD, Gu JG, Cooper BY (2000) Subclassified acutely dissociated cells of rat DRG: histochemistry and patterns of capsaicin-, proton-, and ATP-activated currents. J Neurophysiol 84:2365-2379.

Petruska JC, Napaporn J, Johnson RD, Cooper BY (2002) Chemical responsiveness and histochemical phenotype of electrophysiologically classified cells of the adult rat dorsal root ganglion. Neuroscience 115:15-30.

Pisanu C, Franconi F, Gessa GL, Mameli S, Pisanu GM, Campesi I, Leggio L, Agabio R (2019) Sex differences in the response to opioids for pain relief: a systematic review and meta-analysis. Pharmacol Res 148:104447.

Preuss CV, Kalava A, King KC (2020) Prescription of controlled substances: benefits and risks. Treasure Island: StatPearls.

Price TJ, Inyang KE (2015) Commonalities between pain and memory mechanisms and their meaning for understanding chronic pain. Prog Mol Biol Transl Sci 131:409-434.

Rashiq S, Dick BD (2014) Post-surgical pain syndromes: a review for the non-pain specialist. Can J Anaesth 61:123-130.

Reichling DB, Levine JD (2009) Critical role of nociceptor plasticity in chronic pain. Trends Neurosci 32:611-618.

Reichling DB, Green PG, Levine JD (2013) The fundamental unit of pain is the cell. Pain 1 [154 Suppl]:S2-S9.

Roeckel LA, Le Coz GM, Gavériaux-Ruff C, Simonin F (2016) Opioidinduced hyperalgesia: cellular and molecular mechanisms. Neuroscience 338:160-182.

Rong LQ, Kamel MK, Rahouma M, Naik A, Mehta K, Abouarab AA, Di Franco A, Demetres M, Mustapich TL, Fitzgerald MM, Pryor KO, Gaudino M (2019) High-dose versus low-dose opioid anesthesia in adult cardiac surgery: a meta-analysis. J Clin Anesth 57:57-62.

Scherrer G, Imamachi N, Cao YQ, Contet C, Mennicken F, O’Donnell D, Kieffer BL, Basbaum AI (2009) Dissociation of the opioid receptor mechanisms that control mechanical and heat pain. Cell 137:1148-1159.

Seki S, Erickson KA, Seki M, Nishizawa O, Igawa Y, Ogawa T, de Groat WC, Chancellor MB, Yoshimura N (2005) Elimination of rat spinal neurons expressing neurokinin 1 receptors reduces bladder overactivity and spinal c-fos expression induced by bladder irritation. Am J Physiol Renal Physiol 288:F466-F473.

Silverman SM (2009) Opioid induced hyperalgesia: clinical implications for the pain practitioner. Pain Physician 12:679-684.

Snider WD, McMahon SB (1998) Tackling pain at the source: new ideas about nociceptors. Neuron 20:629-632.

Streicher JM, Bilsky EJ (2017) Peripherally acting micro-opioid receptor antagonists for the treatment of opioid-related side effects: mechanism of action and clinical implications. J Pharm Pract 2017: 897190017732263.

Stucky CL, Lewin GR (1999) Isolectin B(4)-positive and -negative nociceptors are functionally distinct. J Neurosci 19:6497-6505.

Taiwo YO, Levine JD (1989) Prostaglandin effects after elimination of indirect hyperalgesic mechanisms in the skin of the rat. Brain Res 492:397399. 
Taiwo YO, Bjerknes LK, Goetzl EJ, Levine JD (1989) Mediation of primary afferent peripheral hyperalgesia by the cAMP second messenger system. Neuroscience 32:577-580.

Uttam S, Wong C, Price TJ, Khoutorsky A (2018) eIF4E-dependent translational control: A central mechanism for regulation of pain plasticity. Front Genet 9:470.

van Gulik L, Ahlers SJ, van de Garde EM, Bruins P, van Boven WJ, Tibboel D, van Dongen EP, Knibbe CA (2012) Remifentanil during cardiac surgery is associated with chronic thoracic pain $1 \mathrm{yr}$ after sternotomy. Br J Anaesth 109:616-622.

Vierck CJ Jr, Kline RH, Wiley RG (2003) Intrathecal substance p-saporin attenuates operant escape from nociceptive thermal stimuli. Neuroscience 119:223-232.

Vulchanova L, Olson TH, Stone LS, Riedl MS, Elde R, Honda CN (2001) Cytotoxic targeting of isolectin IB4-binding sensory neurons. Neuroscience 108:143-155.

Weisshaar CL, Winkelstein BA (2014) Ablating spinal NK1-bearing neurons eliminates the development of pain and reduces spinal neuronal hyperexcitability and inflammation from mechanical joint injury in the rat. J Pain 15:378-386.

Wiley RG, Kline RH 4th, Vierck CJ Jr (2007) Anti-nociceptive effects of selectively destroying substance $\mathrm{P}$ receptor-expressing dorsal horn neurons using [Sar9,Met(O2)11]-substance P-saporin: behavioral and anatomical analyses. Neuroscience 146:1333-1345.

Woolf CJ, Ma Q (2007) Nociceptors-noxious stimulus detectors. Neuron 55:353-364.

Yi P, Pryzbylkowski P (2015) Opioid induced hyperalgesia. Pain Med 16 [Suppl 1]:S32-S36.

Yildirim V, Doganci S, Cinar S, Eskin MB, Ozkan G, Eksert S, Ince ME, Dogrul A (2014) Acute high dose-fentanyl exposure produces hyperalgesia and tactile allodynia after coronary artery bypass surgery. Eur Rev Med Pharmacol Sci 18:3425-3434.

Zylicz Z, Twycross R (2008) Opioid-induced hyperalgesia may be more frequent than previously thought. J Clin Oncol 26:1564; author reply 1565 